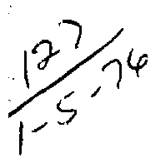

$2-1824$

\title{
A PINHOLE fOR PRODUCING A ClOSE-IN IMAGE OF AN EXTENDED I4-MOV NEUTRON SOURCE
}

Stephen M. Matthews

\section{MASTER}

July 1, 1975

Prepared for U.S. Energy Research \& Development

Administration under contract No. W.7405-Eng-48

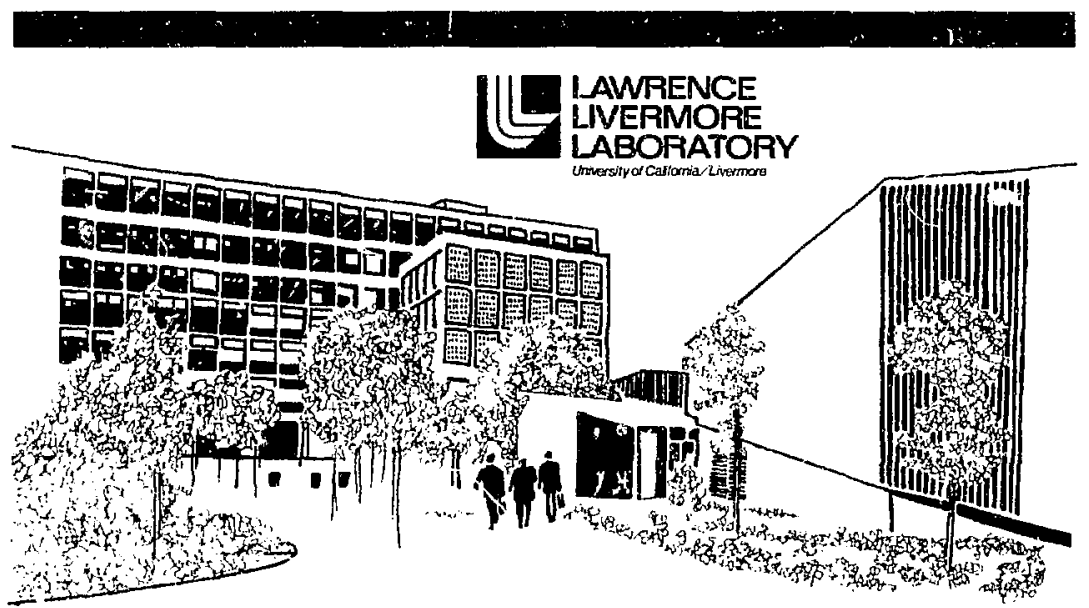


NoTIC i:

"Jhis report was prepared as all account ist work sponsored by the United States Gowerument. Neilhet the United States nor the United States Entres Research \& Development Administratum, not ans of thest employes. Due any of their coniratiors. subcrntsactoss, "If tisct employetes, make's ans wartanty, express or imiplied, or asuuncs any lexat liability or responsibility for the accutacy. completeness or uafulaess of anj informatiun. apparatus, product or process disclosed, or represents that its isse would bot imfringe privately-owned rights."

Printed in the United States of America Available from

National Technical Information Service

U.S. Department of Commerce 5295 Port Royal Road Springfield, Virginia 22151

Price: Printed Copy $\$$; Microfiche $\$ 2.25$

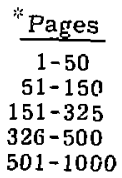

NTIS

Selling Price

$\$ 1.00$

$\$ 5.45$

$\$ 7.60$

$\$ 10.60$

$\$ 13.60$ 


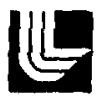

\title{
LAWRENCE LNERMORE LABORATIORY
}

unversity of Caftomia Livermora, Callomia $\$ 4550$

\author{
UCRI- 51860
}

\section{A PINHOLE FOR PRODUCING A CLOSE-IN IMAGE OF AN EXTENDED I4-MEV NEUTRON SOURCE}

Stephen M. Matthews

MS, Date: July 1, 1975

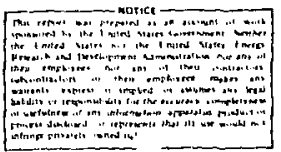




\section{Comernts}

Abseract

I. The basile l'robler.

a Siaple infilole leage

Firice-Thickness Barters, plfe factor, and teaks kenolution . . .

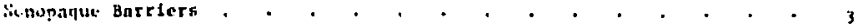

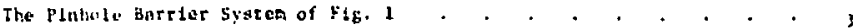

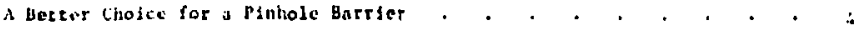

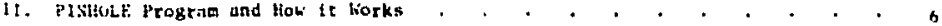

The Geonet $r y$

The Image Screen

tecition of the Polnt Source

The Dynanies of the plisholiz Progras

'HSHOLE Program Outputy

The PIst subroutine

The EXIR Option of the PIst Subroutine

11. A Simple froblem

The PLitiolf. and GudD programs

PIsthol.t. Progran

Jistiole Progran Output

Lulleour Ploks

Data Listing

Unc-dinensional Intenaity Plos

The CRtJ Program

CRID Prograt Oulsue

Ackenot-Ledgent

Appendix I: Complete l.1sting of lishole code

Append Ix II: Complete ilsting of GRID code 


\title{
A PINHOLE FOR PRODUCING A CLOSE-IN MAGE OF AN EXTENDED 14-MeV NEUTRON SOURCE
}

\begin{abstract}
Abwtrart
In pulsed-neucron pinhole saaging experiments it is desirable to produce sanges of extended 14-HeV neveren scurces close tu the nource itself to Minleize :IEe-cr-itight distortions. "Close" guang that the thickness of the pinhole barrler 18 not negligibla in compartson with the distance from the fource to the lage plane.

A pluhale asgembly capable of produrinf cloge-in 1makes if excended 14-HeV

neutron sources has been deslgned and used in a number of cxperiments. A computer program has been devised 50 predict the performance of the pinhole by calculating the distribution of neutrons incident on the lmage plane frum a neutzon point source in the source plane. The calculaction of the tage-plane nautron distr:bution takes into account edge penetration through the barrier and to function beth of the neutron mean free path in the barrier macerial and of the system geometry.
\end{abstract}

\section{The Banic Problem}

\section{A SINPI.E PINHOLE IMAGE}

Cinslder the problem of producing a radiarion 1mage of an extended 14-MeV neutron wource on an lage plane lacated 3 a from the source, with a spatial resolution of 1 the the source and a magnifticton of 2:1. What is the nature of the required pinhole lagaing aysteat The pinhole muse be locazed ane-th1rd of the wil between the source and the image plane (acreen) for che magnification to be $2: 1$. The magniftcation of any pinhole lmage is glven by

$$
H=\frac{z_{E}}{z_{0}}
$$

where $Z_{5}$ it the distance from the pinhale to the image plane and $z_{0}$ is the distance fram the source to the pinhole. The spatial zesolution of the diage is

$$
R=d\left(1+\frac{1}{4}\right) \text {, }
$$

where $d$ is the pinhole diameter and $M$ 1日 the Image magnification.

The resolution R calculated In Eq. (2) 1s the separation between two point sourtes on the bource plane that image as two taugential circles on the lage acreen. Both Eqa. (1) and (2) are strictly valid only for a pinhole made in an Infinicesinally thin barrier that is npaque to the incldent radjecton. Such barrlers do not exist for $14-\mathrm{MeV}$ neucrons. 
FINITE-THICKNESS BARRIERS, PIPE FACTOR, AND IYAGE RESOLUTION

To produce a neutron image with reasonable contrast, the pinhole must be aade in a barrier that is relatively opaque to neutrons (see FIg. 1). Therefore the barrler must have a fintte thickness. This requirement gives rise to a difficulty. The lmages formed by a pinhole through a thick barrier are different for source points near the axis and for source points far from the axis.

Consider a uniform plane source that is imaged as a circle by a pinhole in a fialte-thickness barrier. This image is brightest in the center and becomes pro- gressively dimmer off the pinhole axle due to fncreased pinhole eclipeing. The ratio of the brightness of auch an image at any given point to the brightness of the lmage on the pinhole axis is called the "pipe factor." The pipe factor to unity at the intersection of the pinhole axis and image plane but decreases for pointa on the fmage plane with increasing distance from the pinhole axia. There exists a circle on the image plane centered on the pinhole axis at which the pipe factor becones equal to zero. This circle defines the lmage penumbra. The circle on the source plane that is tmajed as the image penumbra is called the source penumba. No Inage can be formed of source polnts lying outside

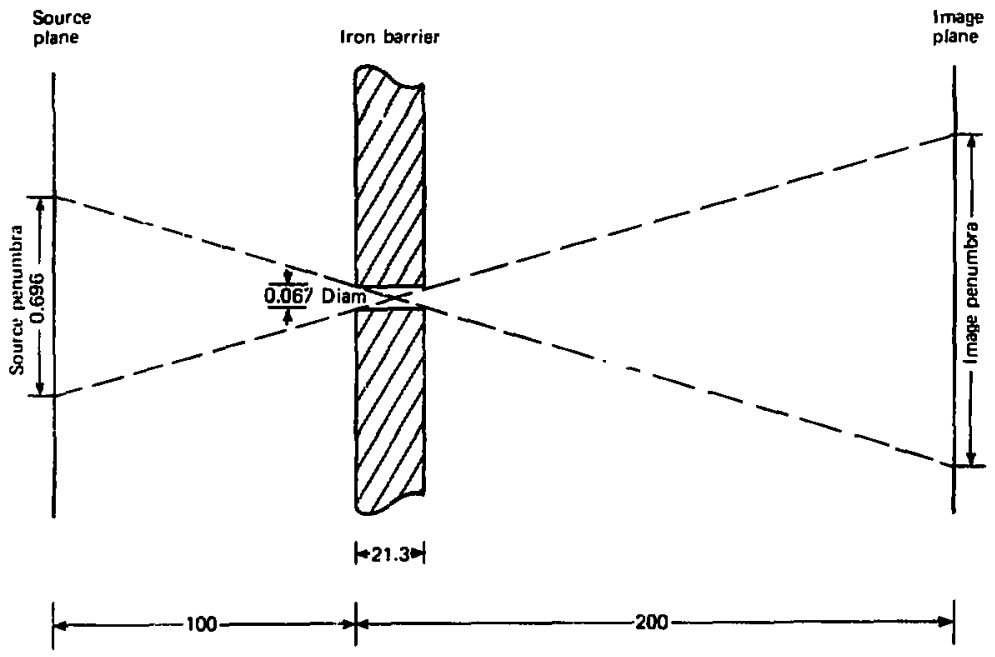

Fig. 1, Poorly designed close-1manging system. 
of on the source nenumbra isecause for thuse poircs the effective pisuole eclipoing 1s total. The size of the suuree penumbra depends on the geometry 1nvolved. The system shown in Fig. I has a source-penumbra dianeter of $0.696 \mathrm{~cm}$.

It $1 \mathrm{a}$ apparent that, for a barrier of fintte thickness, the lange resolution calculated $1 \pi$ Eq. (2) is valld only on the pinhole axis and is a worst case. For source points away from the pinhole axis. the Image resolution becomes better with decreasing pipe factor because the effective pinhole aperture is decreased.

\section{NONOPAOUE BARRIEAS}

It is imposstbie to construct a pintole barrier that is completely ppaque to $14-\mathrm{MeV}$ neutrons since the mean free path of a 14-MeV neutron Is on the order of a few centimeters, even in the materials that are most opague to neutrons. Futthermore, no matter how thick the bartiar. there wil be neutron transmisgion through the front and rear $r$ ths of the pinhole. This "lip penetration" debrades the inage regolution from that calculaced by Eq. (2).

What is a good material ts use for a pimbole barcter for producing $14-\mathrm{MeV}$ neurrun 1mages? A reasonable first cholce could be fron. It ls easily avallable. Is relartvely opaque to 14- $\mathrm{HeV}$ neurrons. and has bacn used extenglvely for neutron collimators." The firat consideration in dusigning a plnhole bartier is itg .hickness. If the bartier is too chin, the

1Edward M. Lent, Collimation of Fast

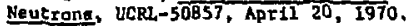

Image contrasc $u: 11$ be low since the resulianc image will be superimposed on a tniform background of neutrons that heve penetrated the barrler. The raximum possible fmage coutrast ( $1 . e .$, the Intensity ratio of the brightegt patt of the tmage to the darkest part) can be no greater than the reclprocal of the neutron transalssion through the bartier. To produce a 14-MeV neutron tmage with a contrast ratio of at least 100, the barrter must have a maxiond neutron $2 .$. . smission of 1\%. Such a barrier wust be at least 4.6 mean free paths thlck, which 1s, for 1ron, $21.3 \mathrm{~cm}$. This barrier is shown in Fig. 1 and will produce the neutron twage described earlier -that 16 , an image located 3 in from the source, with a spatial resolution of $1 \mathrm{~mm}$ and a magnification of 2:].

THE PINHOLE BARRIER SYSTEY OF FIG. 1

We assume that Eqa, (1) and (2) hold approximately for the finite-thickness case. Equation (2) shows that the pinhole dianeter should be 0.67 mo to produce the 1-nim resolution. Equation (1) Indicates that the barrier ahould be placed 1 m from the vource and $2 \mathrm{~m}$ from the Image screen. Kovever, it is unclear what this means since the barrier has a finte thicknese, We locate the barrier as shown In FIg. 1 , with the front of the pinhole exactly 1 m from the source plane. Stwple geometry ahows that the source penumbra has a diameter of only $0.696 \mathrm{~cm}$. The nource can be no larger than $0.696 \mathrm{~cm}$ in diameter and in fact nust be algnificantly amaller than this because a point source imaged wth a zero pipe factor can hardly be considered antisfactory. Such a pinhole is uedess for imaging sources of Interest because the 
maxlmum viewable dlameter of the source 1a not much greacer than the resolution. Furthermore, the resolution w111 be greater than I becauge pinhole lip penetrat ion has not been accounted for. The contrast ratio wils not even $r e 100$ but will be approximately 15 since the barrier cransmission wes deterninit by uning the cotal neutron cross gection-ma value that is correct only for good Beometry. The small distance between the iarrier and the image plane necessitates a worst case calculation, mode with the inelastic cross section to determine the harrier transmission.

The system described in FIg. 1 presents two principal problems:

1. The barrier 1s much too thick to provide a source penumbra giving a large enough view of the source plane.

2. The barrier 18 too thin to provide a good contrast ratio in the bad geometry required to abtain close-in images.

It Is the nicessicy of potatning the 1mage cloje to the source that renders the ubova pinhole system inappropriare. Thls barrier would work well in pradicing art taage with 2:1 magnfflcst ion at, say, 300 m from the source. I.tp penetration cemains a problem in both cases buc is colerablt pro$v$ ided the $p$ ipe factor and contrast ratio are improved.

\section{A BETTEA CHOICE FOR A PINHOLE BARRIER}

Figuie 2 shows a better design for obtairing close-in lomages. As in FIB. 1 , the pinhole diameter is $0.067 \mathrm{~cm}$, but the effective barrier thickness, for gourcepenumbra considerations, $1 \mathrm{~s}$ orly $5 \mathrm{~cm}$ instead of $21.3 \mathrm{~cm}$. The sourcempenumbra diameter 1s increased by a factor of
3.95. Furthermore, the sivart: :jt is considerably taproled. Tle tapered hole through the malr pirt ot the barriar Is the cone of revolutio $r$ th: tef ines the penumbra and has Its apex in the pishole ax's midway between the two pinhole 11ps, Therefore the bulk af $t^{\circ}$ : jarrler does not collimate neutrons or enter Into the source-penumbra calculation, but it does contribuee to barrier opacit:. The total barrler thlekness of $80 \mathrm{cr}$ shown in Flg. 2 is 9.91 inelastic mean free paths for 14-Nev neutrons. The mintmun conerast tat 10 is therefore greacer than $2 * 10^{4}$. Any neutron that scatters off the Inside wall of the front caper ahead of the pinhile cannot pasa through the plnhole athout making a second scater.

The prlce of using the design of F1g. 2 1s the Increased pinhole 11 penetration, wich degrades Image resolution. In fact, the entire pinhole length of $5 \mathrm{~cm}$ Is less than one inelastic mean free pati in 1 ron for 14-MeV neutrons. Hence the barrier can be eas1ly penetrated in the nelghborhood of the pinhole. This 1s not as bad as $1 \mathrm{c}$ might first appear. The cransmission through the barrler drops off exponentially with increesing distance from the pinhole axis, wo thet the on-axis image resolution behaves as though the Image were produced by a pinhole of slightly larger diameter. This can be more than made up for in two ways. First, the pinhole barrier can be moved closer to the aurce plane. This gives Increased magnificetion and 1mproved resolution [see Eq. (2)] but at the cost of decreased source-penumbra diameter. For the design shown in Fig. 2, a magnification of $2.5: 1$ would provide $6.7 \%$ better Inage resolution In conpaz- 


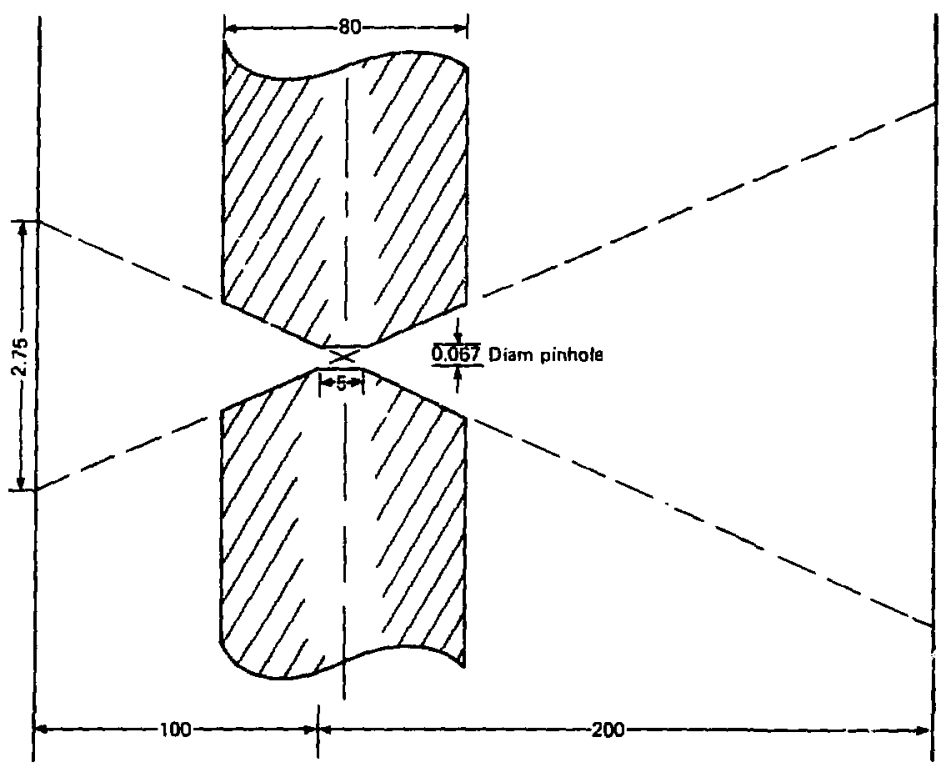

Fig. 2, Better deligned close-1maging syotem.

Ison to a 2:1 magnificstion; however, the source-penumbra diameter would decrease by 13.9\%. Second, the pinhole length of only $5 \mathrm{~cm}$ (compared to 21.3 in F1g. 1) permits drilling the pinhole in a cylindrical insere of exoctc macerial with a smaller mean free path. We have used inserts rade of platinum, which is significantiy more opaque to $14-\mathrm{MeV}$ neutrons than is 1ron. Only a few hundred dollars worth of platinum is needed (even at roday's Inflated prices) because the insert is a very emall fraction of the toral bar$r$ ler volume.

The ibility of a pinhole syster to produce a cloge-in Image can be calculated, consistent with the limitations of barcler nonopaqueness and barrler finte thickness discussed earlier, with the programs Ilsted in the appendices. The pinhole barrler system shown in F1g. 2 w1ll be used as a calculationst model to demonstrate the programs and to familiarize the reader with them. 


\section{P'YHOLE l'rogram und How it Works}

THE GEONETRY

The PIXHOLE program is wsed to calculate the 1mage-productng ability at a pinhole system. It has been used in a number of experiments fo which close-in neutron inages were measured and found $t$ be in agreement with the DIstol. program frediction.

The PIXHCLE program is a ray-tractigg computer program that works for any pinhole system of the general type shown in
Fig. 3. A source pline, an lrage plane. a pluhole and a barrier ar: so defined b: the program that the source and rmage planes are parallet to was weter and perpendicular to rle plahols axiti. A retangulin coordinate system is so defined that the pirhole axi: is the 7-axis and the or$\mathrm{lg}_{\mathrm{g}}$ in is at the center of the pinhole, midway between the front and rear lips. The $Z=0$ plane is the inter piane at tile pinhole barrler. Which is assumed ta be tafintte in extent and to have a thicknest $t$

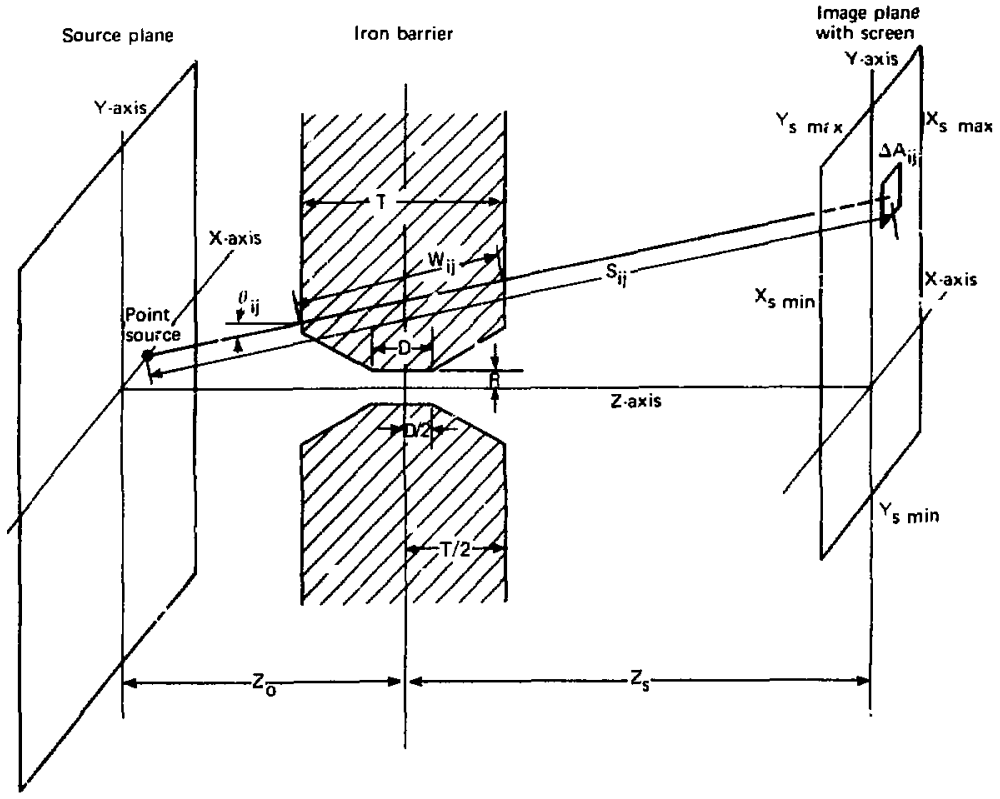

Fig. 3. Geometry for PINHOLE p:ogram. 
sile b, that tise frome ind rear bill ls ot the hartier are the planes $7=-1 / 2$ and $z=$

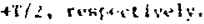

the fllote thself is glien a radius $\mathrm{R}$ and a Itagh $D$ thet is less than $I$. such thet the tront and rear lips are sircles of radius $R$ ? yeng in the $Z=-D / 2$ and $z:+j 2$ planes, respectively. The peruntra cone is defined as the cone swept us: by a : Ine passink through the orfgin ani toth plnhole 11ps. No barrier macerlal is contalned within the pirhole or pesumbra cone. The penumbra cone 1ntersects the source and Image planes at the source penumbra and lage penumba. The source plane $1 \mathrm{~s}$ the plane $z=-Z_{0}$ and the Image plane is the plane $Z=Z_{a}$. The bartler material is assigned, neutron mear froe path $\lambda$.

\section{THE IMAGE SCREEN}

The geonetry and birkiet materia? are defined in the program by setcing the syrbolis defined above equal to numerica: lengths in centimerers. The Image screen Is deftned by choosing a rectangulaz area anywhere on the image plane. This is do:te by specifying two $X$ values, $X_{s \text { max }}$ and $X_{s} m i n$ and two $Y$ values, $Y_{s}$ max and $Y_{s} \mathrm{~min}$. whlch define the screen borders. The screen can be placed anywhere on the inage plane and can be of arbitrary stze. The screen does not have to be symuetrlc sbout the z-axis. The only requirement in defining the screen is that $x$ min

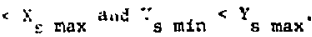

LOCATION OF THE POINT SOLRCE

The lase Item to be defined ts the location of the neutron source. This source is assured to be an lootropic urit pezar source located on the source plane either in the $Z$-axis or at any positive posttion on the $X$-axis inside the source penumbra. It is assumed ic enit isotroptcally a cotal of one partele that has the specteled mean free path in the barrier nate.gal. The location of the point source is defined by Inserting velues for the parameters START, EINIS.7, and DELIA Into the proBran. A sabple fouietn is worked out for the pinnole barcier system of F1B. 2 .

THE DYYAYCS OF THE PISHCEE gROGRAM

When ail the parameters have beun specteled, the screen is broken into an Buo * 800 natrix of equal-area rectangulat elemenzs, each elemenc having an area AA = IXis such that

$$
\therefore x=\frac{x_{s \max }-x_{s \operatorname{mgn}}}{300}
$$

and

$$
\therefore=\frac{\mathrm{Y}_{s \max }-\mathrm{Y}_{s \min }}{800} .
$$

The total distance $S_{1 j}$ irom the point source on the source plans to the center of the element area $A A_{1 j}$ on the lmage screen is calculaied. Aiso, the distance $h_{1 j}$, which is the portion of $s_{1 j}$ that passes through barrier material, Is determined. These distances ale Identified in Fig. 3. The PINHDLE program calculaces both $S_{1 j}$ and $w_{1 j}$ uring equetons that arise from mathematics no more sophisticated than elementary $h^{4}=h$ school trigonometry. Both $S_{1 f}$ and $W_{1 j}$ are tunctions of the Input geometric parameters and the posttion of $\Delta A_{1 j}$ on the 1mage screen. 
Once $S_{i j}$ and $W_{i f}$ are calculated, the following equations are evaluated. First, $\tau_{1 j}$, the transmission coefftctent from the point source through the barrler to the elenent $\Delta A_{1 j}$ is found from

$$
\tau_{1 J}=\exp \left(-\frac{W_{11}}{\lambda}\right) .
$$

The cosine of the angle between the normal to the screen and the ray $s_{1 j}$ from the point source to the element $\Delta A_{1 j}$ is determined. This is given by

$$
\cos \theta_{1 j}=\frac{z_{o}+z_{g}}{s_{1 j}} .
$$

Natice that $1 \mathrm{Eq}$. (4) and everywhere through the program the distance $z_{0}$ is used as a posttive number, even though It measures a langth to the left, or negative, side of the $2-a x i s$ as defined ill Fig. 3. This is because it is conventent to enter $Z_{0}$ into the program as a posttive length. ThIs convention does not apply to the ocher parameters. The Intensity $1_{1 j}$ of the unit point source Incident on the element $\Delta A_{1 j}$ of the seraen is calculated by

$$
I_{i j}=\frac{\tau_{1 j}}{4 \pi\left(s_{1 j}\right)^{2}} \cos \theta_{1 j}
$$

A Do loop In the prograw repeats the calculation of $I_{1 j}$ for each of the $800 \times 800$ matrix elemente $\Delta A_{1 j}$ on the screen.

\section{PINHOLE PROGRAM OUTPUTS}

The calculation produces a twodimensional image-Intensity profile of the unit point source. This profile hes a mesh of $800 \times 800$, which is $f$ Ine enough for most applications. The output for the profile it in the form of a contour plot over the screen dimenslons. Five contour levels are platted at 99,50 , 25, 10 , and $1 \%$ of the maximum intensity on the screen. The maximum intensity $I_{\text {max }}$ is determined by the equation

$$
I_{\max }=\frac{1}{4 \pi\left(s_{\text {max }}\right)^{2}} \cos \theta_{\max }
$$

where $S_{\max }$ is the straight-line distance from the point source through the origin to screen and $a_{\max }$ is the angle that $s_{\text {max }}$ makes with the screen normal.

In addition to the contour plot at the gereen intensticy level, the PINHOLE progran gives a list of calculated values and Input geometrical factors. These are descrlbed below.

Integra1

This term is used to calculate the total number of particles incident on the chosen screen. It is found by summing over all the $I_{1 j}$ values of $E_{q}$. (5) and multiplying the sum by $\triangle A$ :

$$
\text { Integral }=\Delta A \sum_{1,1}^{800,800} I_{1 j^{\circ}}
$$

The integral. Is of particular importance for neutron Image sampling of an extended source. In this case the PINHOLE calculation is performed with a screen reduced in size to that of an individual neutron detector. The calculacion is then repeated with the detector fixed but with the unit polnt source displaced slightly to a new location on the source plane. The integral resulting from each calculation is the number of neutrons incident on the small detector as a function of position of the polnt source on the source plane.

The background signal that arises when an extended source is 1maged is due to 
those neutrons that artive at the detector by femetrating the barter materlal rather than by passing throigh the pishole. The background from a given unit point source on the source plane can easily be calculated by using a U1fference method. A source is placed at the given point, and the difference between two integrals is found. The first integral is calculated frum the experimental parameters of the pinhile system and is the total number of neutzons arriving at the detector. The second integral is calculated with the mean free path of the barrler material changed to an Infinitesimal value to render the barrier artificially opaque. This second integral is the number of neutrons arriving at the detector by passage through the pishole only. The difference between the two integrals is the background at the given detector position from the giten unit point source. An estimated total background from an extended source can be obtained by integrating this kind of background calculation over the source.

\section{Peak Intens 1ty}

The peak intensity is the numerical value of $\mathrm{I}_{\text {max }}$ calculated in $\mathrm{E}_{q}$. (6).

\section{Pinhole Radius}

The pinilule radius 15 the value of the Input parameter $R$ showis in Fig, 3 .

\section{Plobole Length}

The pinhole length is the length designated D in Fig. 3.

\section{Barrier Thickness}

The barrier thickness is the value $\mathrm{T}$ shown in Fig. 3.

\section{Neutron Mean Free Path}

This parageter is the neutron mean free wath in the barrier material.

\section{Radius of Source Penumbre}

The source penumbra has been defined earlier. A point source located outside the source penumbra cannot be 1maged by the pinhole. The program calculates tiis radius by using the equation

$$
R_{S P}=2 R\left(Z_{o} / D\right)
$$

\section{Source Plane to Front of P1nhole}

This is the distance $l_{1}$ of the front pinhole lip from the source plane. It is given by

$$
\ell_{1}=z_{0}-D / 2 .
$$

\section{Eront of Pinhole to Image Plane}

This is the distance $\ell_{2}$ between the front pinhole lip and the tmage plane. It is given by the equation.

$$
\mathrm{R}_{2}=\mathrm{z}_{\mathrm{s}}+\mathrm{D} / 2
$$

\section{Image Magnification}

The magnification $M$ is glven by the equation

$$
M=l_{2} / l_{1}
$$

where $\ell_{1}$ and $\ell_{2}$ are found from Eqs. (9) and $(10)$. Equation (11) is most nearly correct only for an opaque barrier. How ever, it does provide a fairly clese approximation to the real expected magniflcation, which is actually a slowly 
varying function over the image plane. The magafication calculated by Eq. (11) is also useful when checklng the inaging properties of the plahole barrier system with a 1 ight source.

\section{Image Resolution}

This is che resolution detfrmined by Eq. (2) using the value of $M$ calculated by Eq. (11). This resolution is correct only for as opaque barrier. The true trage resolution must take into account barrier ponecration and pinhole lip penetration. This can be determined by a epecia! variation of the PINHOLE program called GRID, whIch can calculate the image of a number of unit point sources placed side by side.

\section{Time-ot-Ellght Constant}

The purpose of placing the pithole close to the source is to keep neutron tidge-offlfght distortions at a minimum. The timeof-flight constant is the time-of-flight spreading of $914-\mathrm{MeV}$ neutron signal with an energy spread of $1 \mathrm{MeV}$. The value comes from the olople classtcal relation

$$
\frac{\Delta E}{E}=2 \frac{\Delta t}{t}
$$

where

$$
\begin{aligned}
\Delta E= & 1 \mathrm{McV} \\
E= & 14 \mathrm{MaV} \\
t= & \text { flight time of a } 14-\mathrm{MeV} \text { neutron } \\
& \text { over the distance } \mathrm{z}_{0}+\mathrm{z}_{\mathrm{s}} \\
\Delta \mathrm{t}= & \text { the time-of-fight constant. }
\end{aligned}
$$

\section{THE PINL SUBROUTINE}

The PINI subroutine performs a calculation similar to the PLNHOLE calculation but In one dimeasion. The output consists of several plots, the most important betng the unit polnt source image intensity along the $X$-axis of the screen.

The PIN1 subroutine divides the $\mathrm{X}$-axi; of the screen Into 800 linear increments and the calculates the total distance along each ray connecting the unit point source with each lijear element on the $x$-axis of the screen. The length of that part of each ray passing through the barrler is also calculated. The intenstty profile along the $X$-axi- of the screen is then calculated by an e uation analogous co Eq. (5) and plotted is a function of position al'ng the screen in the $X-$ direction. Both the Intensity ari the log of the intensity are plotted.

The calculation is then repeated with the mean free path of $14-\mathrm{MeV}$ neutrons in the barrier matertal changed from its entered value to a very small number to represent an almost perfectly opaque macerial. A plot $t_{s}$ made of the screen intenstey function for an opaque barrier, and this is superimposed over the plot of the intensity function caliulated with the real barrier. Thts superposition tmmediately reveals the effects of pinhole $11 \mathrm{p}$ penetration on the image.

Each of the 800 rays traced by the PINI subroutine has 1 ts barrier entrance and extt coordinates graphed on an $x, 2$ plot. The plot of these points forms an outline of the pinhole barrier. 
THE FXTRA OPTION OE THE PIN 1 SUBROUTINE

The PlN subroutine contains an option for calculating the effect of increasting the thicknesi at the rear of the barrier with extra material of the same mean free path as the original borrter, as shown in 118. 4. Thts option ts exercised by entering a value for the parameter ExTkA in the parameter entrance part of the program. Indeed, some numerical value of this dimension that is greater than or equal to zero but less than $z_{s}-T / 2$ must be entered or the program will not run. The contour plot of the PINHOLE program assumes a barrier of thickness $\mathrm{T}$ only. However, the PINI subroutine is run through twice, the first pass with the barrier thiciness set equal to $T$, as shown in FIg. 3, and the second pass with the bartier set equal to $\mathrm{T}+$ EXTRA, as shown in F1g. 4 .

Source

plane
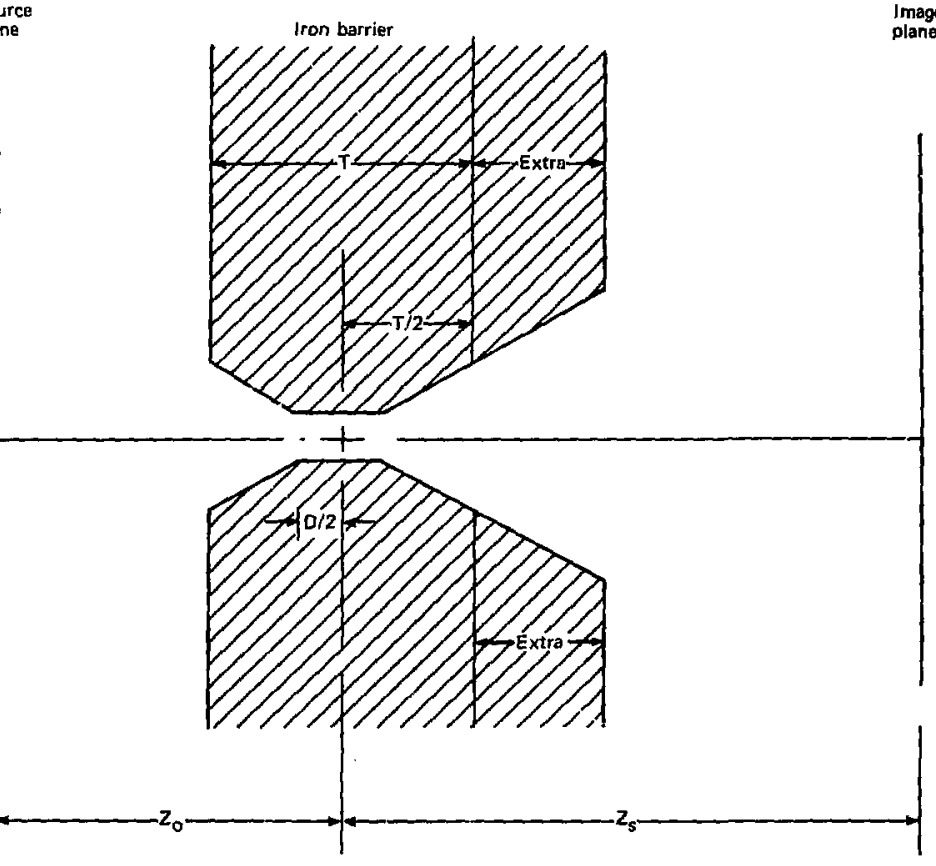

F1g. 4. IIIustration of EXTRA option. 


\section{A Sample Problem}

THE PINHOLE AND GRID PROGRAMS

The pinhole bartier system shown in Fig. 2 is calculaced as a sample problem using the complete PINHOLE and GRID programs, which are listed in Appendices $I$ and II. The GRID program performs essentially the same calculations as the PINHOLE program but allows the simultaneous imaging of two or more unit point sources. This is quite useful in checking image resolution since the distance separating the sources can be reduced unt1l they cannot be Individually imaged. When this occurs, the $1 I_{\mathrm{mit}}$ of resolution has been reached.

In both the PINHOLE and GRID programs there are 14 parameters that must be entered or the programs will not fun. All the parameters are entered in the begining of the program after the CALL CR'EID card, as listed in Appendices I and II.

\section{PINHOLE PROGRAM}

The sample problem consists of lmaging four unt polnt sources with the barrier syster of Fig. 2. The first parameter is plnhole radius, which $1 \mathrm{~s} 0.033 \mathrm{~cm}$. A card Is punched out with the entry

$$
\mathbf{R}=0.033 \quad \text { (entry } 1 \text { ) }
$$

and Inserted into the deck as shown in Appendix I. Each of the other parameters is entered by punching 1 ts values on computer cards and entering the cards into the deck as shown below and In Appendix I. All dimensions entered into the PINHOLE and GRID programs mute be in centimeters.
The pinhole length as shown in Flg. 2 is $5 \mathrm{~cm}$. Therefore a card is punched

$$
\text { D } 5 \text {. }
$$

The pinhole barrier thickness of the Iron barrier is $80 \mathrm{~cm}$ :

$$
\mathbf{T}=\mathbf{B 0} .
$$

The mean free path of radiation in barrier material $1 \mathrm{~s} 8.07 \mathrm{~cm}$ :

$$
\text { AVFP }=8.07 \quad \text { (entry } 4)
$$

The source plane distance from center of barrier $1 \mathrm{~s} 102.5 \mathrm{~cm}$ :

$$
70=102.5
$$

Note that this parameter is entered as a positive number, even though the source plane is at $z=-102.5$.

The 1mage plane distance from center of barrler is $297.5 \mathrm{~cm}$ :

$$
Z S=197.5
$$

The $Z$ S entry above defines the image plane, but not the screen posftion on the 1mage plane. A rectangular screen of any size may be placed anywhere on the Image plane Inside or outside the penumbra. The screen does not have to be centered on the pinhole axis. For the purpose of this sample calculation we shall choose a square screen $5.2 \mathrm{~cm}$ on a side and centered on the pinhole axis. The edges of such a screen are obviously at $\mathrm{X}= \pm 2.6 \mathrm{~cm}$ and 
$Y= \pm 2.6 \mathrm{~cm}$. This screen $1 \mathrm{~s}$ defined by entering the screer's endge values as follows:

$$
\begin{array}{rr}
\text { XSMAX }=2.6 & \text { (encry 7) } \\
\text { XSMIN }=-2.6 & \text { (entry } 8 \text { ) } \\
\text { YSMAX }=2.6 & \text { (encry 9) } \\
\text { YSMIN }=-2.6 & \text { (entry 10) }
\end{array}
$$

A unit point source $1 \mathrm{~g}$ placed on the source plane at the orlgin or on the positive $x$-axis Inside the source penumbra. When the calculation is compleced, it is usually comvenient to move the source :o a new location ant repeat the calculation with the other parameters flxed. We shall lllustrate how this 1 s done by first placing a source at the origin and then moving It 0.4 cm and repeating the entire calculation. This is repeated each time moving the source point by $0.4 \mathrm{~cm}$ from its previous location until the source point arrives at $:=1.2 \mathrm{~cm}$. The calculation $1 \mathrm{~s}$ then terminated.

The shaRT position of the source polnt is the crigin of the source plane. This is specified by the entry

START $=0$.

(entry 11)

We degire the calculation to FINISH, or terminate, when the source arrives at $x=1.2 \mathrm{~cm}:$

$$
\text { FINISH }=1.2
$$

The pulnt source ts co be moved by $0.4 \mathrm{~cm}$ for each succersive alculation. He specify this with the entry

$$
\text { DELTA }=0.4
$$

These START, F1NISH, and DELTA entries wll produce four separate calculations with the geometry defined earlier. The unit poinc source $w 111$ be located at $X=0$, $X=0.4, X=0.8$, and $X=1.2$. A complete calculation on the LLL-7600 takes approxImately 30 seconds of computer time per source point.

The EXTRA option as deftned earlier must be entired for the program to rup. even though it is used only in the onedimensional calculations of the PINI subroutlne. This parameter is defined in Fig. 4. We shall choose an EXTRA barrier thickness of $40 \mathrm{~cm}$ additional to be added to the rear of the $80-\mathrm{cm}$ barrier, bringing the total bartier to a thickness of $120 \mathrm{~cm}$. This is done by entering

$$
\text { EXTAA }=40 .
$$

(antry 14)

The two-dimensional outpuc of the PtNHOLE program docg not recognize EXTRA and its calculations use only the Ba-cro barrier. Then the PINI subroutine performs onedimenstonal calculations using first the 80-cm bar-ier and then a barrier of $(80+40) \mathrm{cr}$.

\section{PINHOL.F, PROGRAM OUTPUT}

We obtaln four sets of putput from the sample calculation since four separate positions of the unit point source were entered. The output resulting from the first caleulation with the unit polnt source on the ortgin of the source plane is shown in Figs. 5a through 51.

The contour plot of FIg. 5a is the intensity procile on the screen chosen. The computer has picked a coordinate system in which the sereen appears to be a $6-\mathrm{cm}$ 


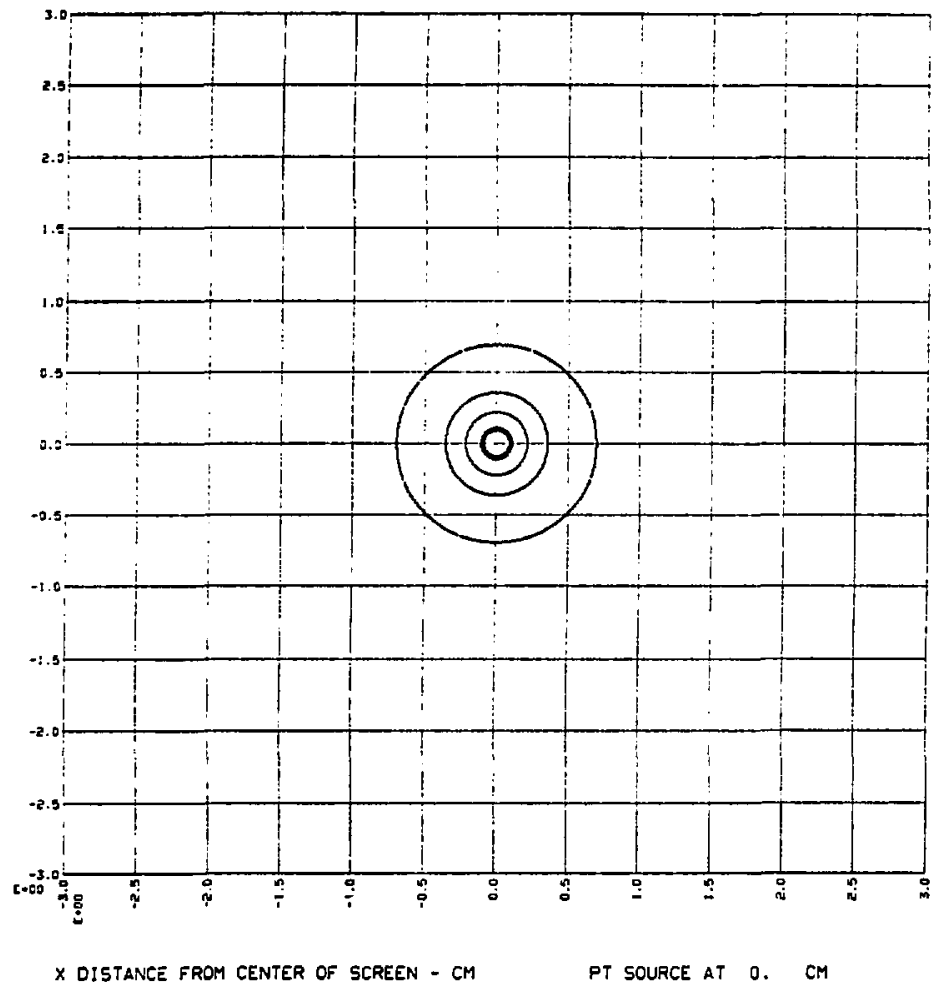

F1g. 5a. Contoux plot of gcreen for sample problem with point source at $X=0$.

squste, but the calculation is extended only over the 5.2-cm-square acreen used as Input to the program. The results show contours at the $99,50,25,10$, and $1 \%$ Intens1ty levels. The contours appear as circles centered about the origin of the Image plane, as wnuld be expected for an on-axis point $5.1, \ldots$ The lower right cor- ner of the figure shows the point source is at $x=0, \mathrm{~cm}$, which $1 \mathrm{~g}$ the or $1 \mathrm{gin}$ of the source plane.

A listing of the inpui and calculated parameters appears in F1g. 5b. The 1ntegral of 1.41 E-07 counts is the number of neutrons incident on the chosen screen from an on-axis unit point source that emits

(text continues p. 20) 
INTEGFAL

PEAK INTENSJTY

PINTCLLE RADIUS

PINATLE LENGTH

SOLFEE FENUMERA RADIUS

GAPR:ER THICKNESS

NEUTREN MEAN FREE PATH
$1.41 E-07$ COUNTS

8.84E-07 COUNTS, Sa CH
SOUREE Planie to front of PINHOLE

FRONT OF PINHDLE TO IMLGE PLANE

IMAGE MAGHIFICATION

IMAGE RESOLUTION

T. O.F. CONSTANT
80.00

8.07
0.033 CENTIMETERS

5.00

1.35

\author{
100.00 \\ $2 \div 0.00$ \\ 2.00 \\ 0.10 \\ 2.05 NS, MEV \\ PT SOURCE AT O. CM
}

F18. 5b. Date liating for sample problem with point source at $X=0$. 


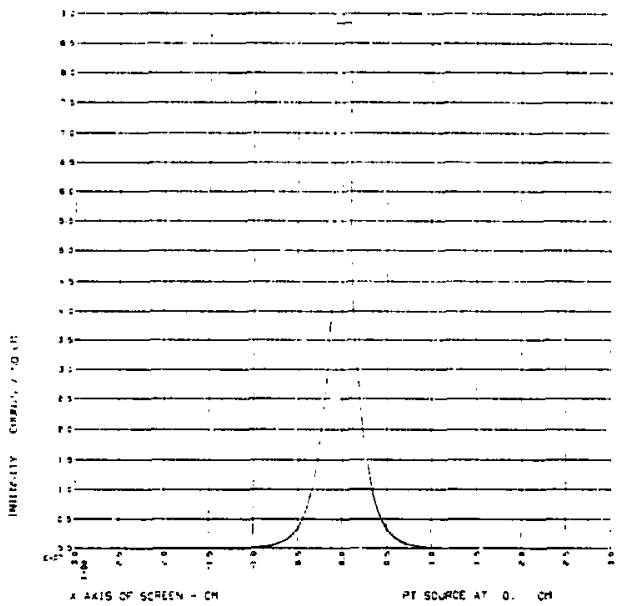

Fig. Sc. One-dimensional linear Intensity on screen.

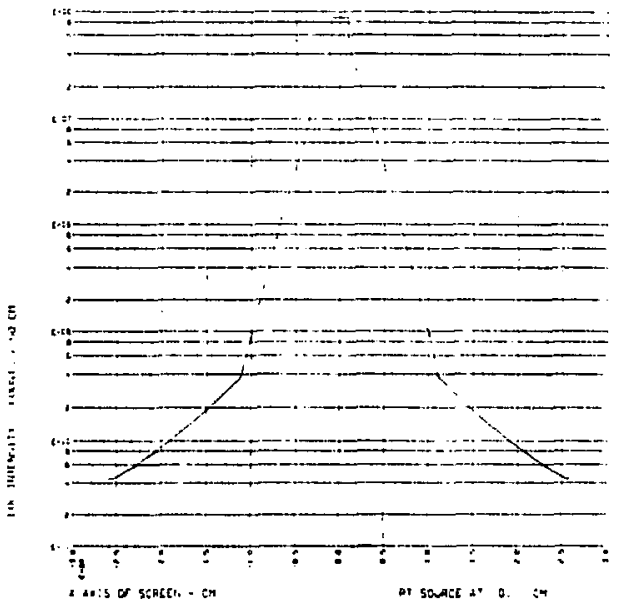

Fib. Sd, Ond-dimantonal log Intenetty on ecreen, 


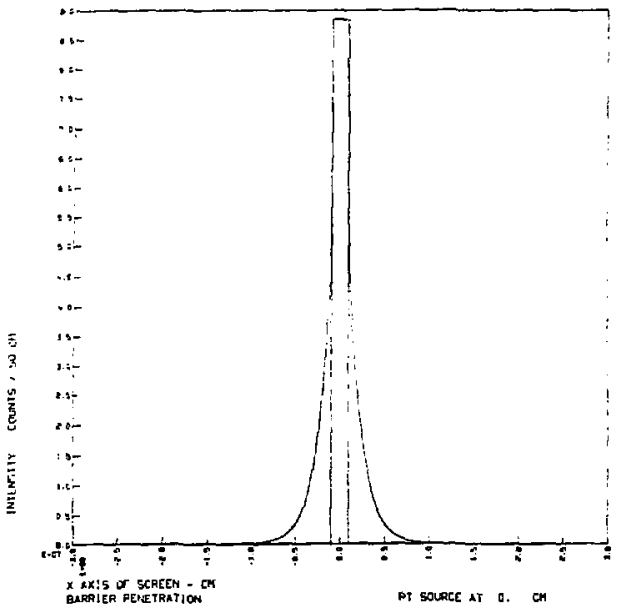

Fig. 5e. Point-8ource 1mage produced with opssyize and nonopaque barriers showing lip penetration.

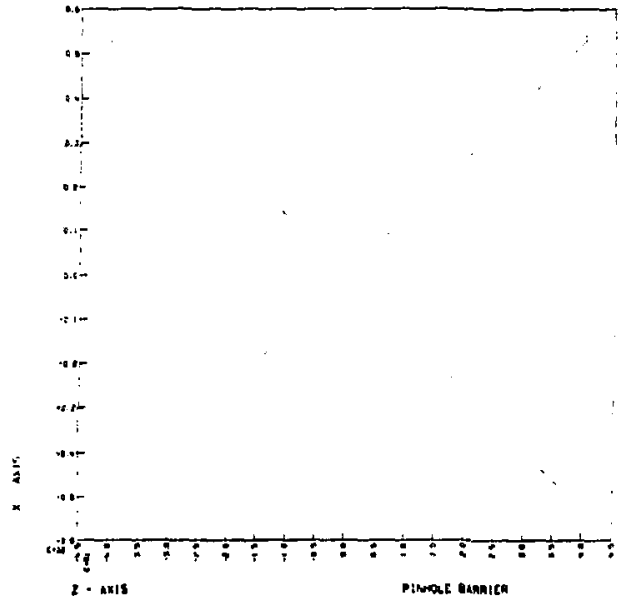

F1s. 3f. $X, 2$ plot of ray ontrance and exit polint: through barriet. 


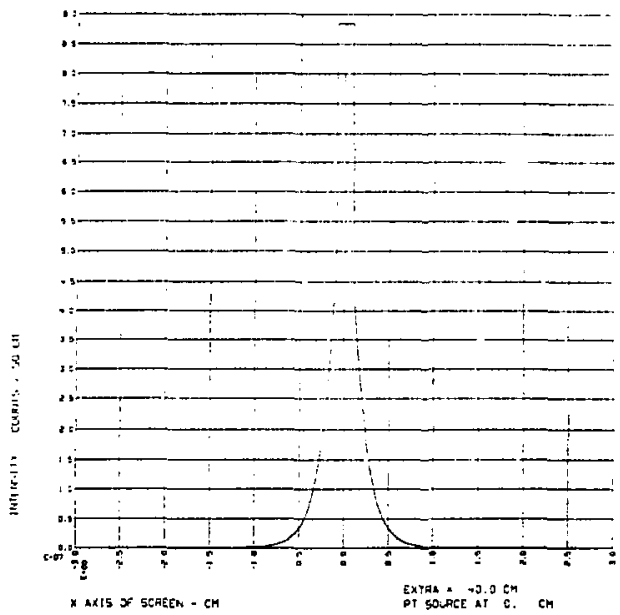

F18. 58. Linear intensity on screen using EXTRA option.

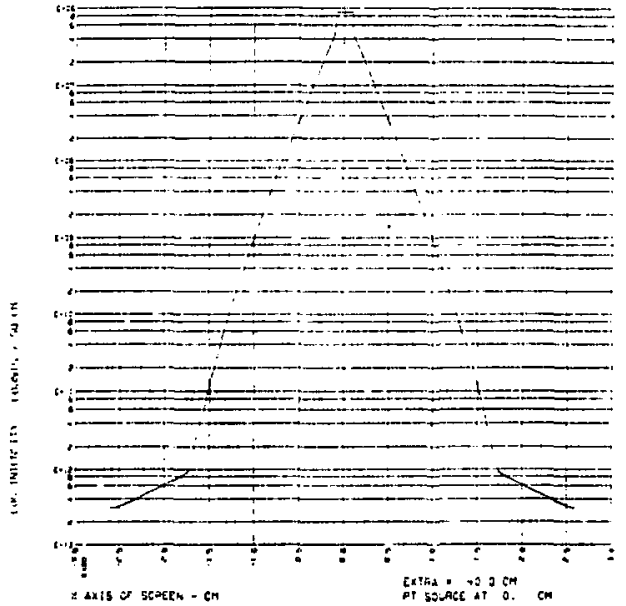

Fig 5h. Log Intenalty on acreen using ExTRA option. 


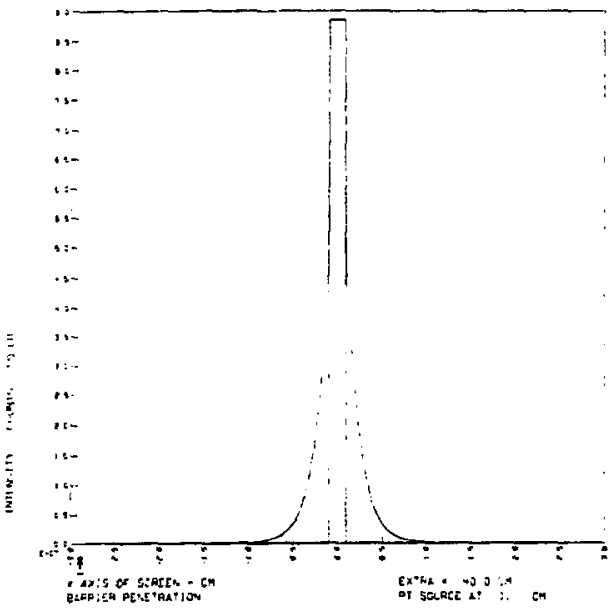

F1g. 51. P1nhole 11p peretration with EXTRA option.

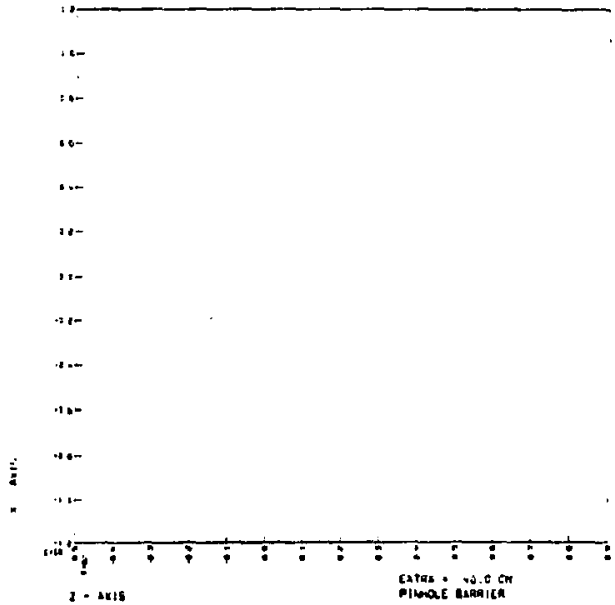

71. 5j, My entrance and exit pointe through berrier with ExtRa option, $x, 2$ plot. 
isotropically over $4 \pi$. The peak intensity of $8.84 \mathrm{E}-07$ counts $\mathrm{cm}^{-2}$ is the value $I_{\max }$ of Eq. (6) and is the value on which the contours of Fig. 5a are based. The remainder of the listing consists of the input parameters and the calculated parameters descrlbed earlier.

Figures $5 a$ and $5 b$ are the only two $f 1 g-$ ures that are direct output from the PINHOLE program. The rest of the figures (Figs. 5c-5j) result from the PINI subroutine. Figure $5 c$ is a linear onedimensional intensily plot across the $\mathrm{X}$-axis of the screen resulting from the unit point source at $X=0 . \mathrm{cm}$ on the source plane. The $\log$ of the intensity is shown in Fig. 5d. Figure 5e shows the result of a lincar superposition of two ${ }^{2} \eta-$ tensicy plocs; one $1 s$ a repeat of the $11 n-$ ear plot described earlfer, and the other is the result of a calculation using an infinitesimal mean free path in the barrier material. The effect of barrier penetration ts clearly apparent in Fig. 5e.

An $X, Z$ plot or the entrance and ext pulnts through the pinhole barrier of the rays traced from the point source to the screen is shown in Fig. 5f. These points clearly outline the pinhole barrier.

Figures $5 \mathrm{~g}$ through $5 \mathrm{f}$ are repeats of -igs. 5c through $5 f$ with the EXTRA bartier talckness added. It is clear from the plots that in this example the EXrRA thickniss of $40 \mathrm{~cm}$ added to the rear of the barrier has very little effect on the Inear intensity of tile tmage, but it does reduce the background by approximately two o! lers of magnitude.

The above degcribed output is the complere output frcu the program for a unit point source at a designated postion. Thls calculation used about 30 stconds of LLL-7600 computer time. The point source is moved to $\mathrm{X}=0.4 \mathrm{~cm}$ on the source plane, and the entire calculation 1 s repeated. This process is concinued until the point source arrives at $\mathrm{x}=1.2 \mathrm{~cm}$ on the source plane, moving in steps of $0.4 \mathrm{~cm}$, after which the calculation is terminated.

We shall not show all the data obtalned for each source point but only the contour plots (Figs, 6a-6c), the data liscing (Figs. $7 a-7 c)$, and the one-dimenstonal intensity plots showing the effects of barrfer penetration (Figs, $8 a-8 c$ ).

\section{COSTOUR PLOTS}

As the point source moves in the positive $x-d 1$ rection on the source plane, the Image moves in the negative $x$-direction on the screen. The 1mage movenent is approximately twice the source movement. This is characteristic of a pinhole camera with a magnification of $2: 1$. As the source is moved further off axis, the resulting image becones less and less ctrcular.

When the point source is as far as 0.8 $\mathrm{cm}$ from the origin of the source plane, the resultant 1mage is distorted enough to cause a characteristte butterfly distortion at the $50 \%$ intensity level. This is the resulc of asymetric pinhole 11 penetration. At a displacement of $1.2 \mathrm{~cm}$, the contour plot is noi large enough to be seen clearly un the chosen screen. This contour can be shown in better detall by rerunning the calculation with a smaller ecreen cencered about the Irage. 


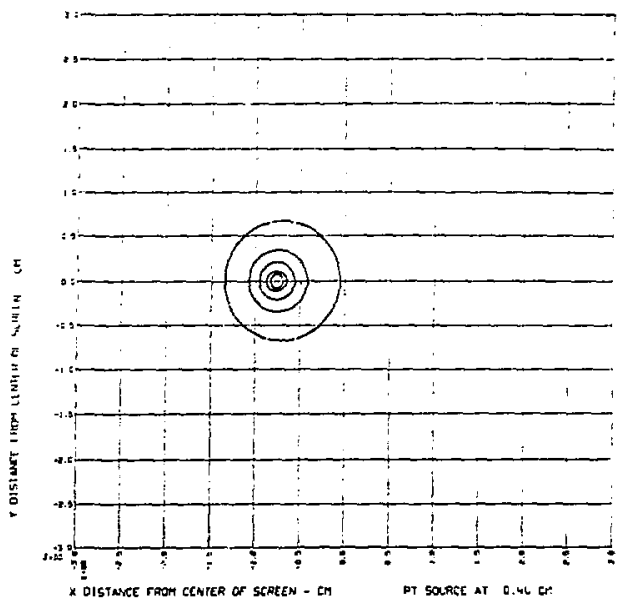

FIg. 6a. Contour plot for sample problem with source at $x=0.4$.

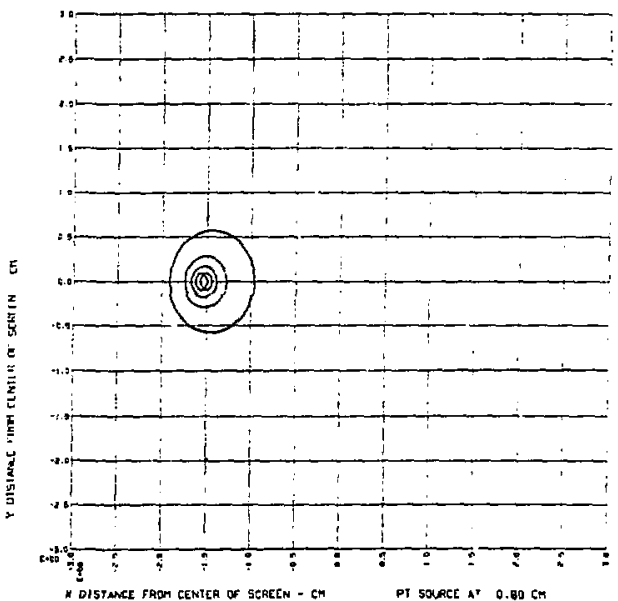

Fig. 6b. Contour plot for gample problem with source at $x=0.8$. 


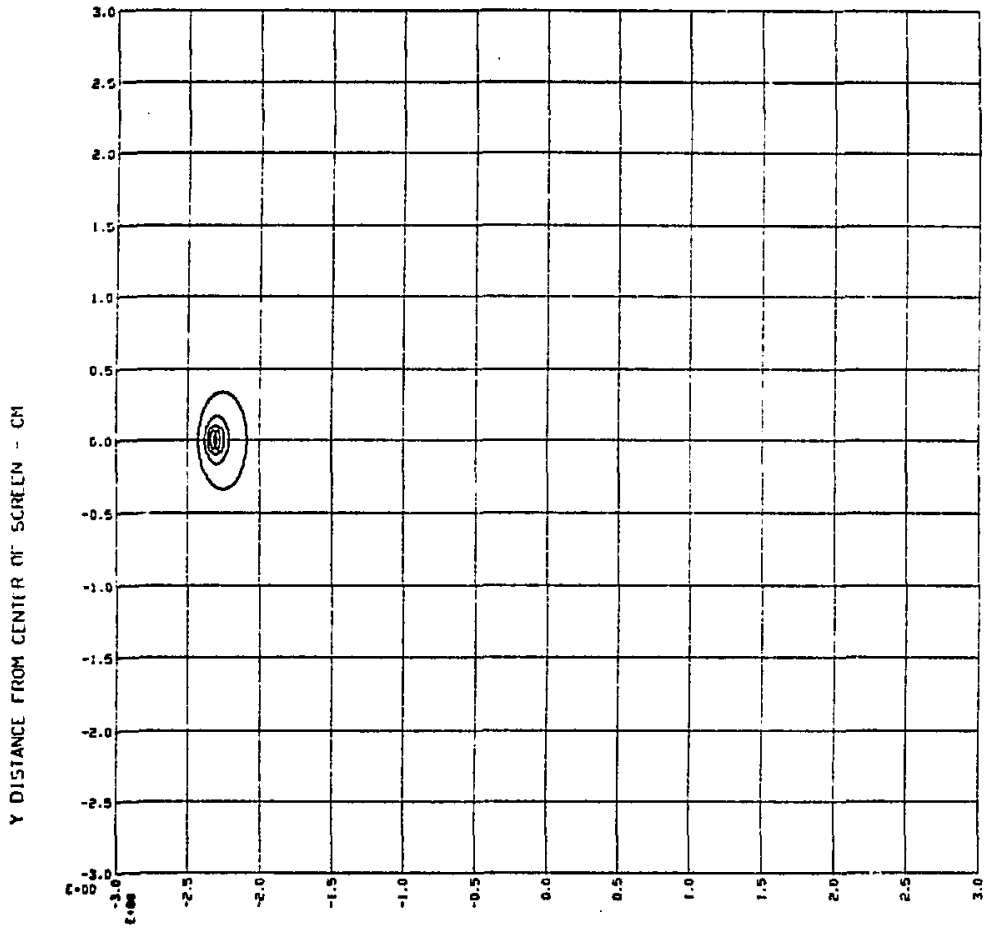

$X$ DISTANCE FROM CENTER OF SCREEN - CM PT SOURCE AT $1.20 \mathrm{CM}$

F1g. 6c. Contour plot for sample problem with source at $x=1,2$.

DATA LISTING

The displayed data shown in Fige. $7 \mathrm{a}$, 7b, and $7 c$ indlcate that the number of particles arriving on the screen decreases as the source gets closer to the source penumbra. The integral for a source $1.2 \mathrm{~cm}$ off axis is 1.99 E-08 counts compared to 1.41 E-07 counts for an on axis source. These numbers are, of course, a function of the screen stze. Had a smallor screen been chosen--for example, a 2-cm-square screen centered on the origin--then the integral from the on-axis source would have been 


\begin{tabular}{|c|c|}
\hline$\because z: \pi_{n}$ & 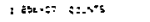 \\
\hline 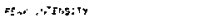 & 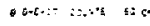 \\
\hline $2,-: E$ ALD:S5 & 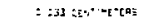 \\
\hline$\therefore--2.5$ : ens: : & $\pm:$ \\
\hline 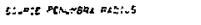 & ; $\mathbf{s t}$ \\
\hline 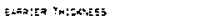 & $60: \pm$ \\
\hline 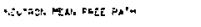 & $6 .=$ \\
\hline 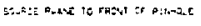 & $\because:::$ \\
\hline 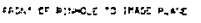 & $2=: \therefore$ \\
\hline 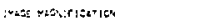 & z: \\
\hline 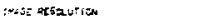 & $\therefore \therefore$ \\
\hline :EAF Constant & $2 \mathrm{KE}$ is, $\mathrm{rzk}$ \\
\hline
\end{tabular}

Fig. 7a. Data Iisting for sample problem with source at $X=0.4$.

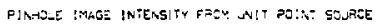

$\because \cos _{\mathrm{i}}$

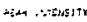

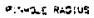

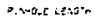

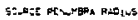

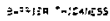

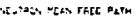

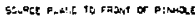

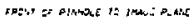

tane reatiorseatish

inate atseivilon

1. e.F. Cosin' an'

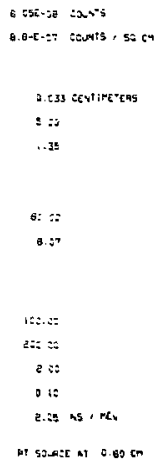

ho gon:5 at $8.60 \mathrm{~cm}$

F18, 7b. Data linting for sample problem with source at $X=0.8$. 


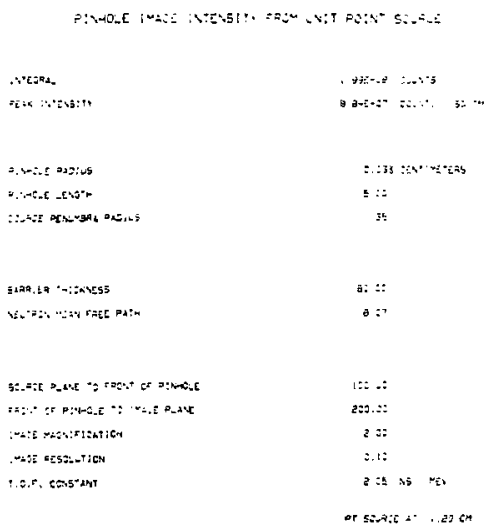

F1g. 7c. Data listing for sample problem with bource at $\mathrm{x}=1,2$.

slightly smaller, and the integral from the point source 1.2 cm off axis would have been substantially smaller since most of the image would have missed the screen.

Notlce that the peak Intensity would not change in the above example. The peak 1 ntensity is not the peak Intensity on the screen, but is the $I_{\text {max }}$ or Eq. (6).

\section{ONE-DLMENSIONAL INTENSITY PLOTS}

The PIl: subroutine plocs shown In Figs. $8 a, 8 b$, and $8 c$ show basically the same results displayed in the contour plots. The Image becomes narrower and barrier penucration becomes more pronounced as the point source is moved further from the origin of the source plane.

THE GRLD PROGRAM

To 1llustrate the GRID program we again use the system that was calculated In the previous example; that $1 \mathrm{~s}$, the system shown 1n Fig. 2 with the EXTRA option set at 40 cm. The geometric parameters are entered In exactly the same way as with the PINHOLE program example, except for the entrles that define the point source (see the GRID program I1sting In Appendix II).

We shall calculate the effect of placing six untt point sources side by side on the $\mathrm{X}$-axis of the source plane, each source separated from its neighbor by $0.2 \mathrm{~cm}$. As with the PINHOLE program, the sources are restricted to the orlgin or the positive $x$-axis of the source plane within the source penumbra. The first source will be placed at the origin. This is specified by entering a card

$$
\text { START }=0 .
$$
(entry 1)

There are to be a total of six sources 


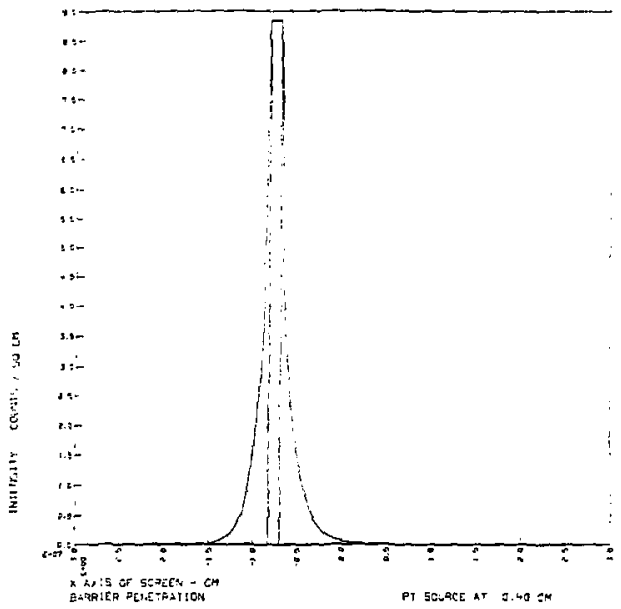

F1g. 8a. PInhole 11.p penetration for sample problem with source at $\mathrm{X}=0.4$.

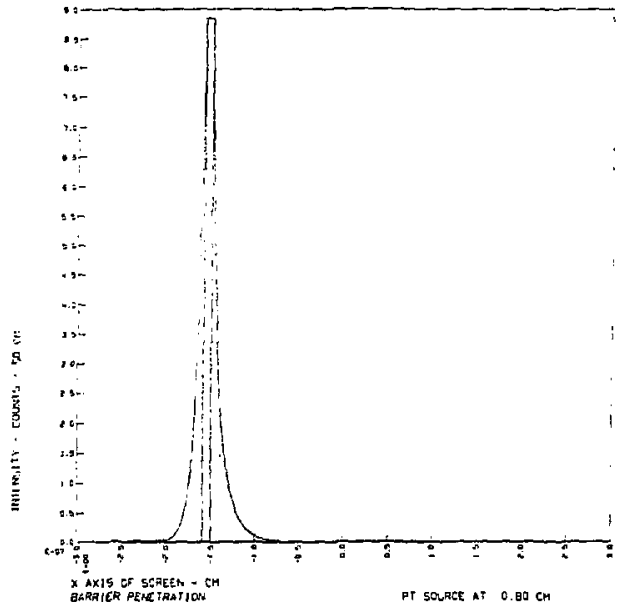

FIg. 8b. PInhole Iip penetration for sample problem with wource at $X=0.8$. 


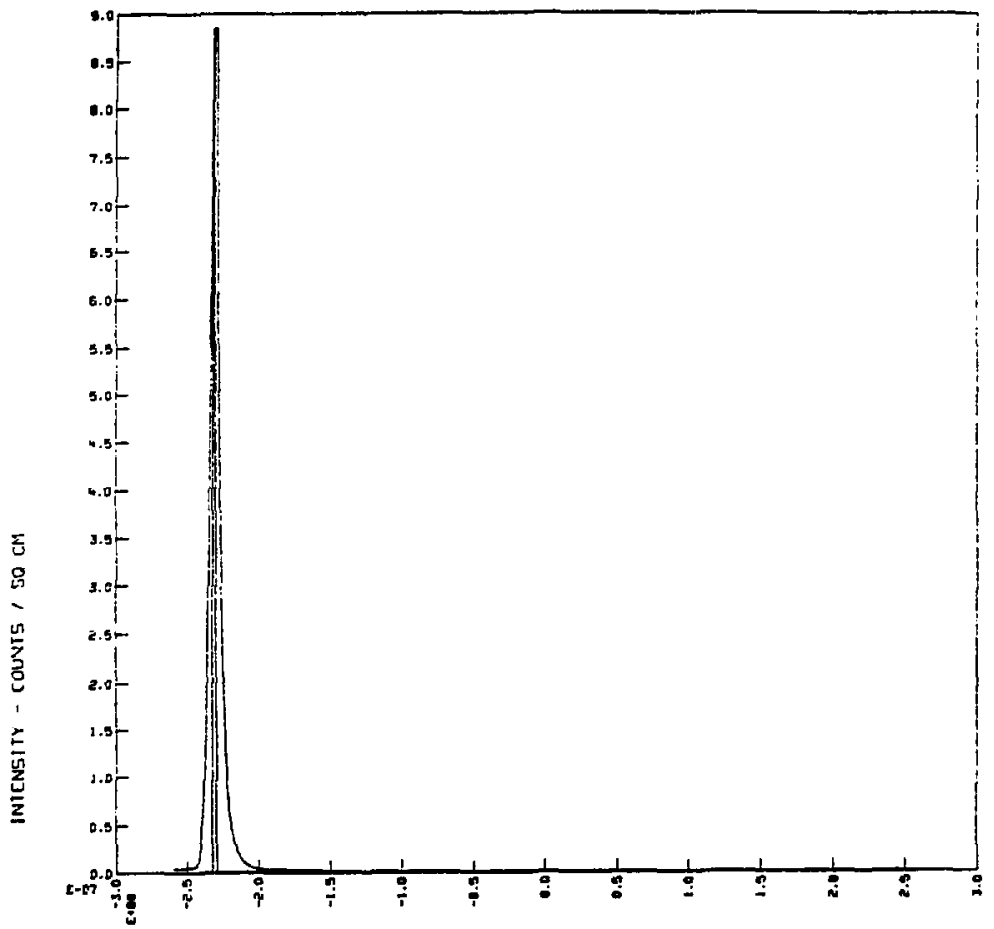

PI SOURCE AT 1.20 CM

Fig. Bc. Plphole I1p penetration for anple problem with oource at $X=1.2$.

each separated by $0.2 \mathrm{~cm}$. Therefore the cards

$$
\begin{aligned}
\text { NUMBER } & =6 \\
\text { DELTA } & =0.2
\end{aligned}
$$

(entry 2)

(entry 3) are entered in the appropriate place as shown In the GRID prog-am 11sting. A11 other entries are the same as with the PINHOLE program. A total of 14 entries must be made or the prograg will not run. The GRID program w1ll now calculate the Image produced by $\mathrm{g} I \mathrm{X}$ unit point sources placed along the $X$-axis of the source plane at $X=0 ., X=0.2, X=0.4, X=0.6$, $x=0.8$, and $x=1.0$. The entire calcula- 
Han at six pulats In this s.tmple problem

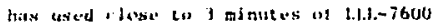
ompuler 2 ime.

\section{GRID PROCRAM OUTPUT}

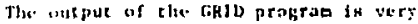
siglier to that of the PIsHOL.k prograth. Figures 9il, 9b, and 9. shitw some of the
GHI prograt output. Figure 9 is is the conuur plot with rentours at 99, 50, 25.10. and 17 of the peak intensity. The peak fntenglig value of 1.05 E-06 counts $\mathrm{cm}^{-2}$ listed in Flg. $9 b$ is the perk Intensity incident or the sereen and is not bhe value $I_{\text {max }}$ of Eq. (6) as in the Ptshole prograf uutpuc. The integral valuc shows a tolat

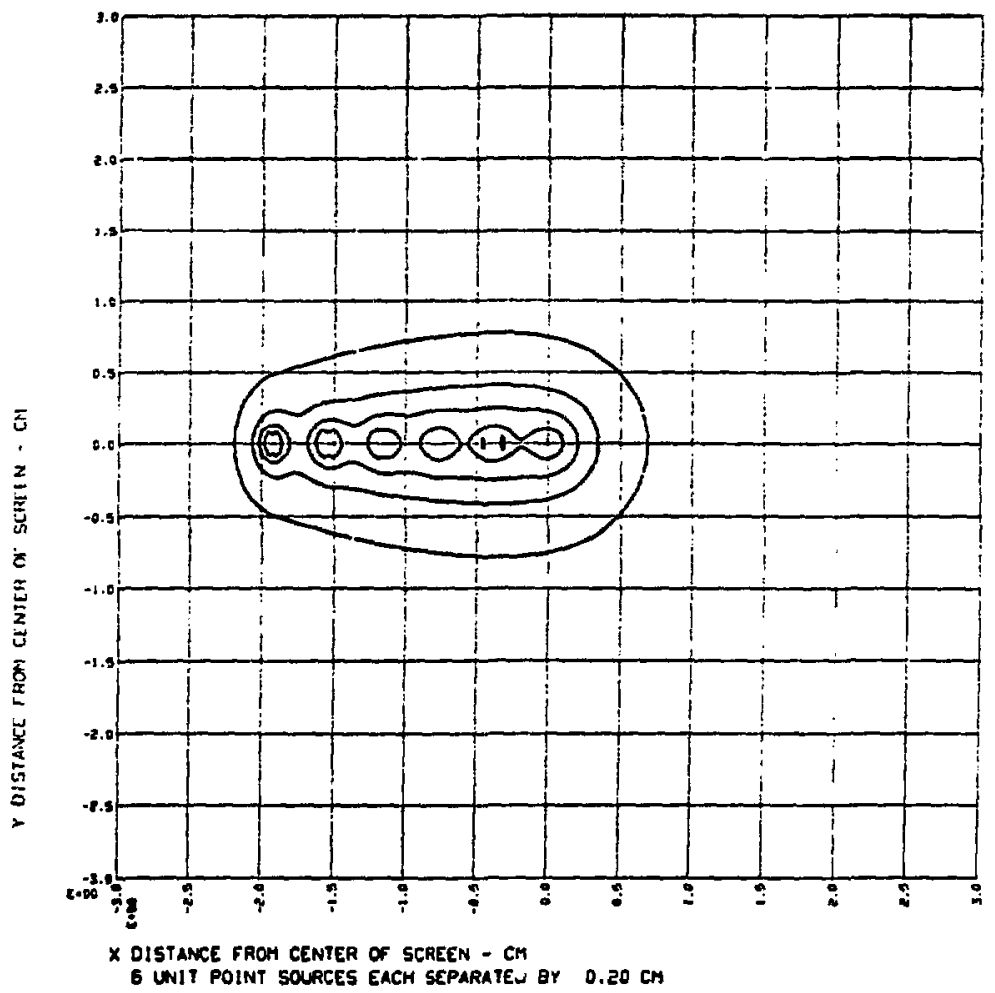

F1g. 9a. Contour plot uElng GRID prograti--gources resolvable. 
:acesas.

WELK INTENSITY

Pininge ALOIS

Pinatit micaness

sagist ditamera madius

GLFaIER Tatencss

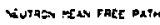

S2. DEE D.AME "S TACHT CF PINHOLE

rapart of Pirnge io IMage PLARE

THas mavirtcation

J Haoe atsonitica

T. O.F. CCASTaNT
6. 4GE-6) Canis

1.03E-96 COUMTS / $50 \mathrm{~cm}$

0.033 EEnTHETERS

5.20

I. 35

0. 2

0.07

100.28

200.30

3.30

0.10

2.05 N5, MV

6 wir point Sounces tale separafed oy $0.20 \mathrm{ch}$

F1g. 9b. Data listing from GRID program using six sourceu.

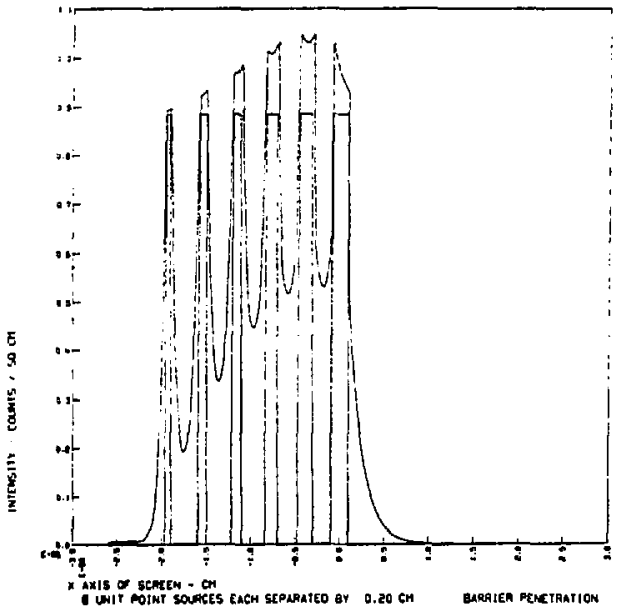

F18. 9c. Lip penetration doea not destroy 1mage zenolution. 
of 6.40 E-07 councs incldent on the chosen screen from the six dsotropleally emitting unit point sources. The one-dimensional output shown in Fig. 9c is the result of calculation using both the real burrier and an artificlally opaque barrier with the mean free path sec equal to an Infinitesimal value. Figures $9 a, 9 b$, and $9 c$ show that point sourcea placed $0.2 \mathrm{~cm}$ apart along the $X$-axis of the source plane can be resolved fairly well whth this gysten.

We shall now repeat the GRlD calculation with 14 unft point souries placed $0.1 \mathrm{~cm}$ apurt along the $x$-axis. This is done by changing the encry NTMBER from 6 to 14 and the entry DELTA from 0.2 to 0.1 . The results of this cajculation are shown in Figs. 10a, 10b, and 10c. The concour plot

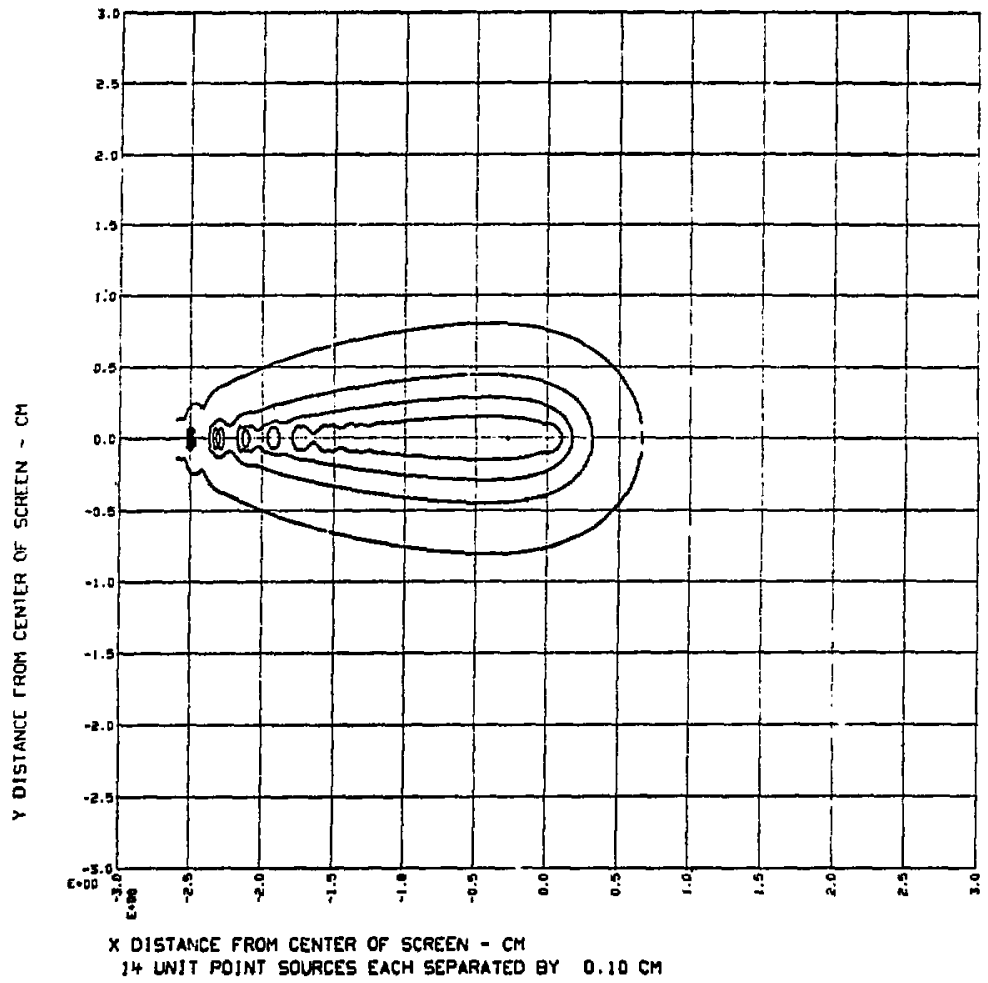

FIg. 10a. Contour plot from GRID program showe 14 points that cannot be resolved, 
$\because$ TGaA.

De $14.5+5 ! m$

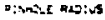

piv-c,e milakess

3EATSE PEIATHA RADIUS

पAFAIER PNICARESS

P.FAK FAN TREE OATM

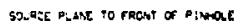

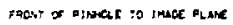

; wate men!f jeatior

imsite RESOLUTION

†.O.F. conspart

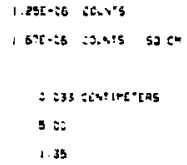

5 :

1. 35

晓

a. 0

100.35

200.20

3.00

0.10

wos is , Res

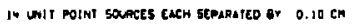

F1g. 10b. Data liating from GRID program uoing 14 source polnts.

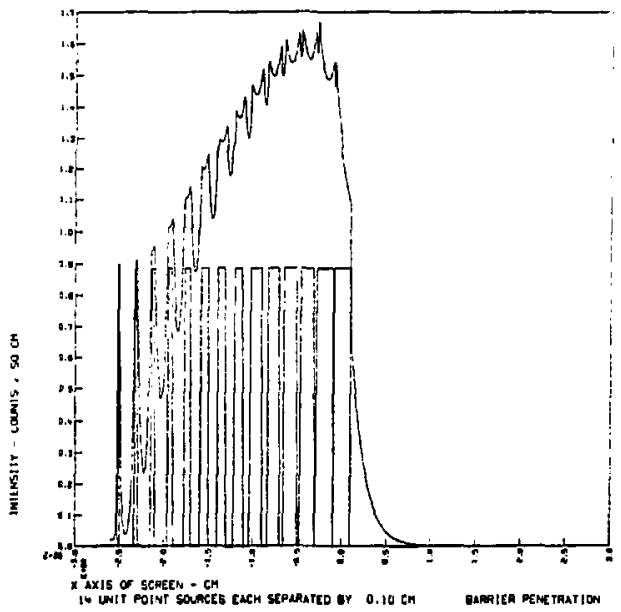

Fig. 10c. Pintole lip panecration deatroys resolution over most of Image. 
Flg. 10ir shows that individual soureas ranoot be resolved by this $\$ y 3 \mathrm{sem}$ when stparated by $0.1 \mathrm{~cm}$ and placed near the orfgin of the source plane. The sourcen can be resolved near the penumbra because the acllpaing effect of the finlte-thickness barrier results in a smaller effective pinhole diameter. Figure 106 shows that the cotal number of counts reaching the screen has Increased to $1.25 \mathrm{E}-06$. which $1 \mathrm{~s}$ almost double the Incldent counts when 5 Ix soirces were used. The calculated number of counts does not Increase by exactly $7 / 3$ since the pipe-factor consideration Is implicit wich-
In the calcuiation. The peak intensity increased from 1.05 E-06 co 1.67 E-06 counce $\mathrm{cm}^{-2}$ malnly as a result of increased superpostition or plling up of tmages from sources close to the or $1 \mathrm{~g}$ th of the suurce plane. This is precisely the result of a fallure of the system to resolve each gource indivldually.

This effect is dramatically illustrated In Fig. 20c, in whlch the resolucion fatdure near the center of the source plane is seen to result frow the pinhole Itp penetration effect.

\section{Acknowledgment}

The author thanks Raymond A. Heinle of LLL-Nevada, who Independently produced a similar computer program, for his many helpful remarks and suggestions. 


\section{APPENDIX I}

COMPLETF. LISTING OF PINHOLE CODE 


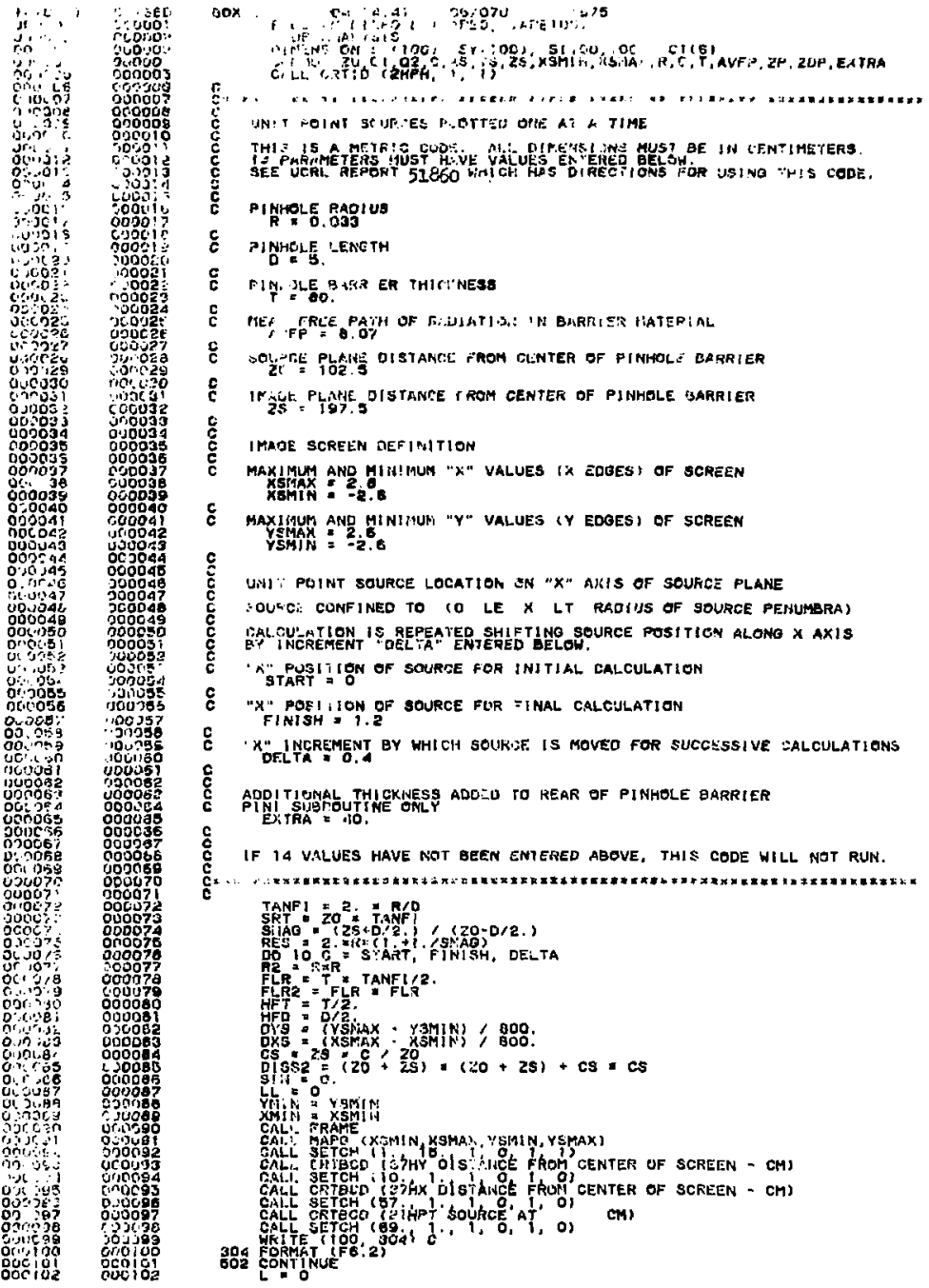




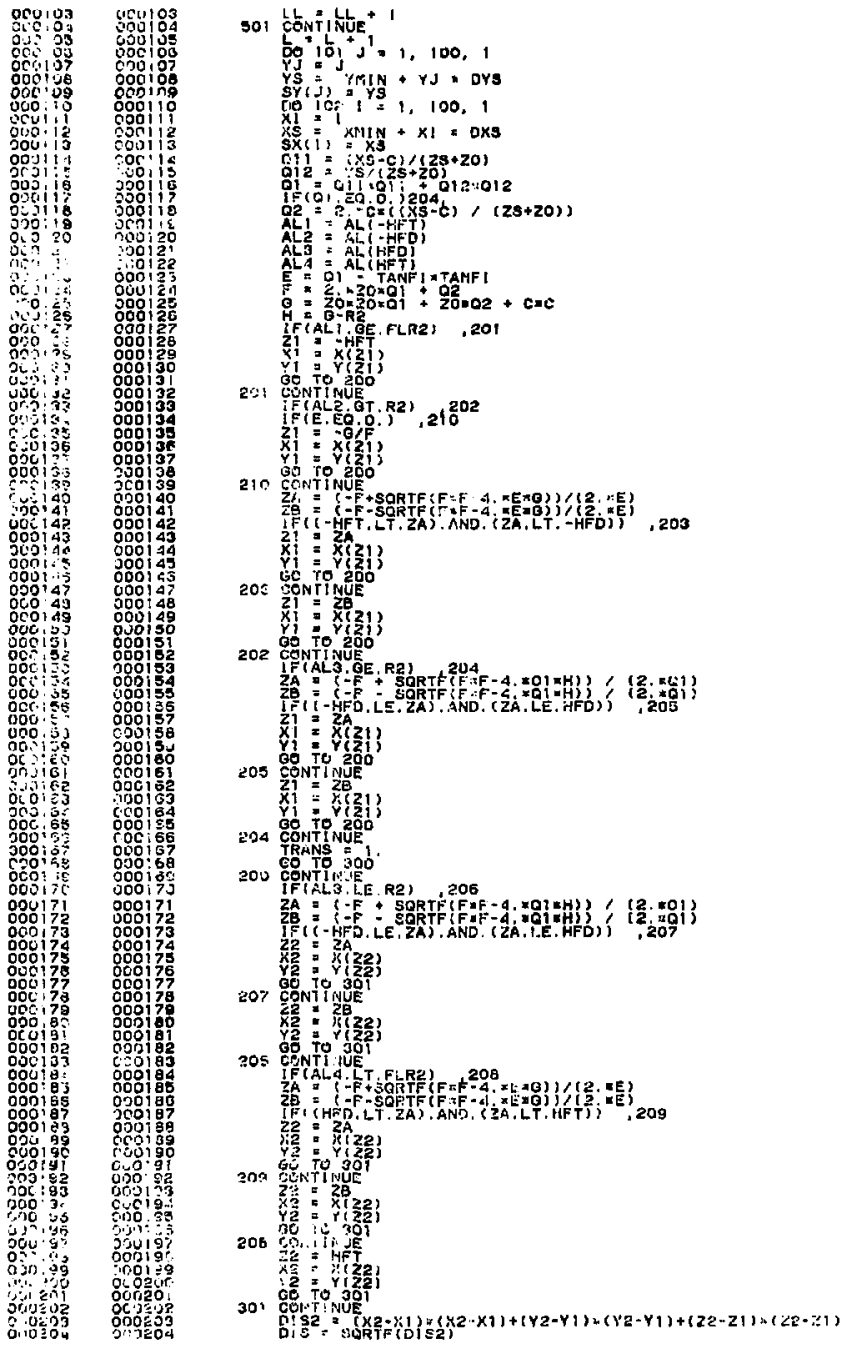




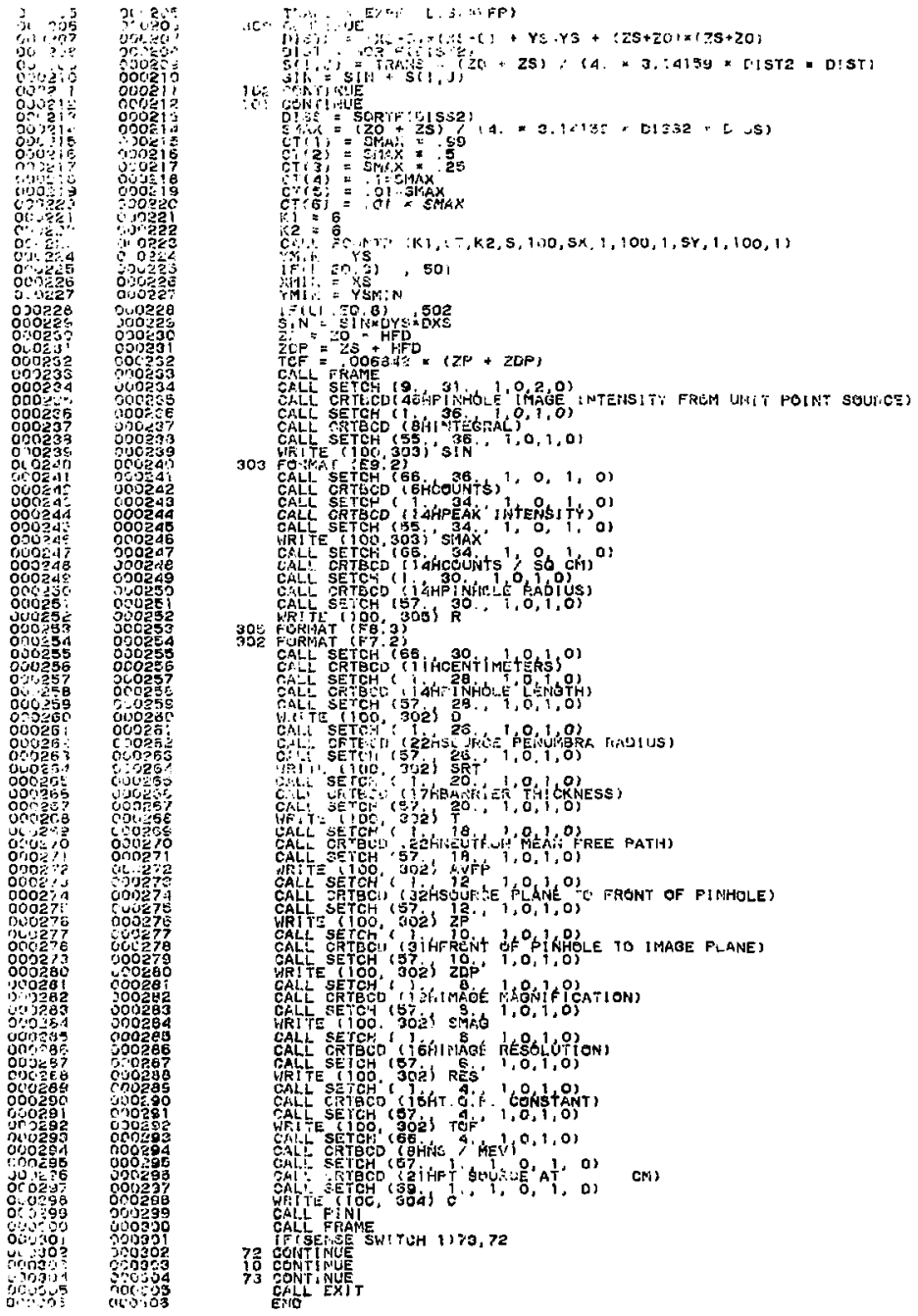




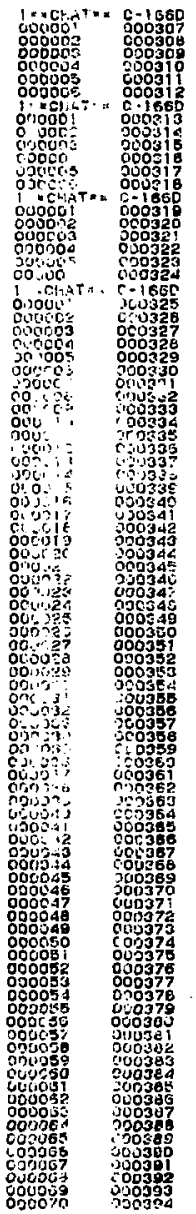

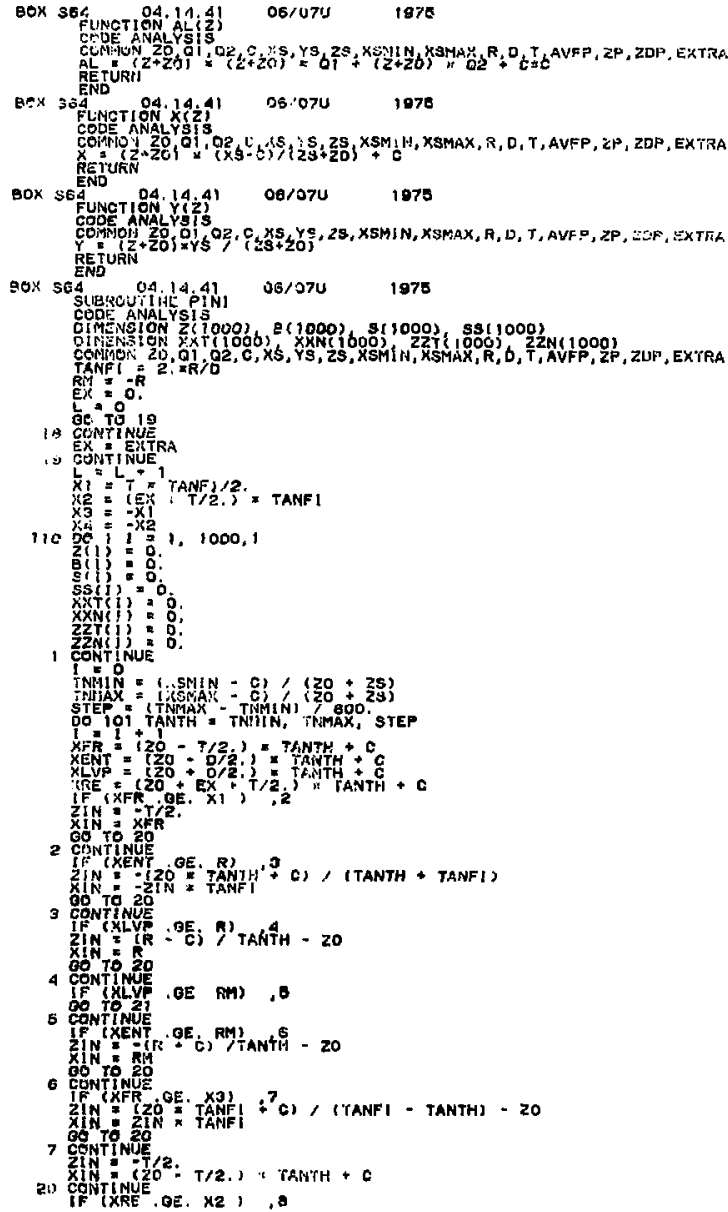




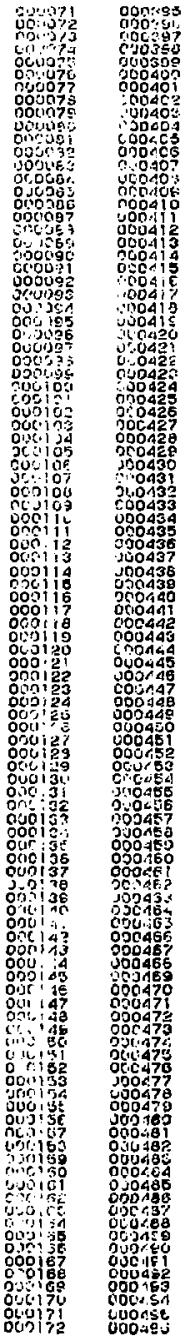

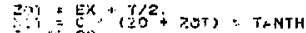

-

ROT

GQ Tu

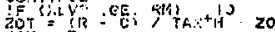

10 $=\mathbf{n}$

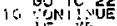

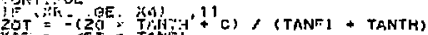

Tanit

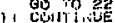

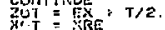

22 :

27-

21 goviñus

$7=0$.

Ge. To4 104

104 GONTINUE

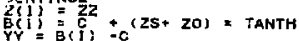

$\bar{Y}=B(\hat{I})-C$

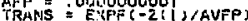

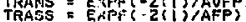

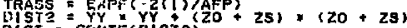

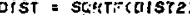

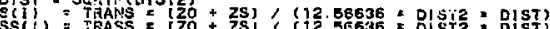

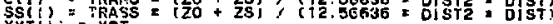

XYT(i) = XOT

XuN (i) $=x i$

ZZTí = ZOT

101 Cisti NUE

$Y$ YIN = XSNIS

CALL CABTMM(1, SMIN, JIAX, s, 1)

CALL MAOOYMIN, YIAX, O

CALL SEYCRT (B, $s^{3}, 1 ;$; Oj

CALL SETCH ( $B$ : 5 to

CALL SETCH ( 2 , 5 . $1,0,1,1$ )

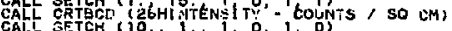

CAIL CSI

CAIL SETČH (57)

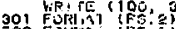

(agi, $1,1,0,3,0$

To $F^{+}$

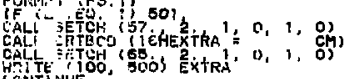

so:

ONTINUE

OAL PRAME

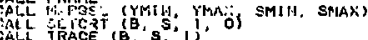

(B) 3,1$)$,

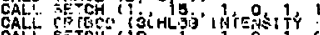

SALTH (10

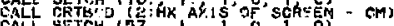

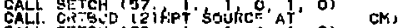

CAL StSC (

WRITE (TOO, , ऊOIŚ

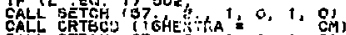

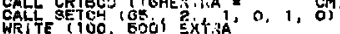

bar

DOPTINUE.

CALL MAPST YMIN, YMB, C., SHAX ?

CALT. SLTgRT ( $\mathrm{B}, \mathrm{s}, 1 ; \mathrm{O})$

OALL QETCPT (S, ss,

CAL SETCH (1: is $1,0,1,11$

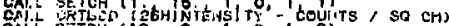

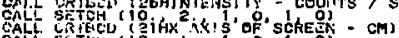

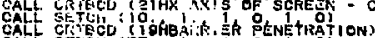

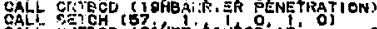

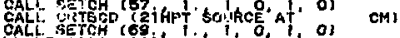

WALTE (foo, gois c.. i, o, i, O)

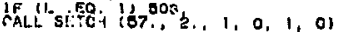



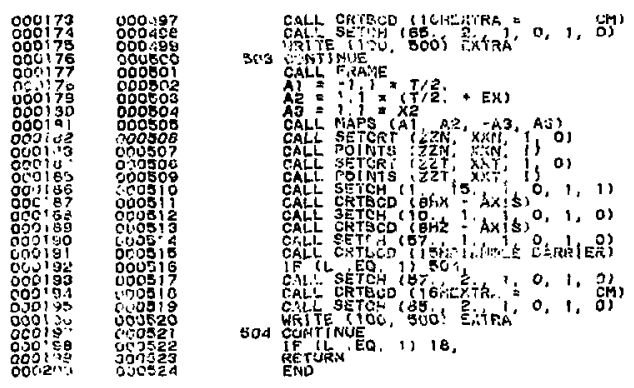


\section{APPENDDX II}

\section{COMPLETE LISTING OF GRD CODE}




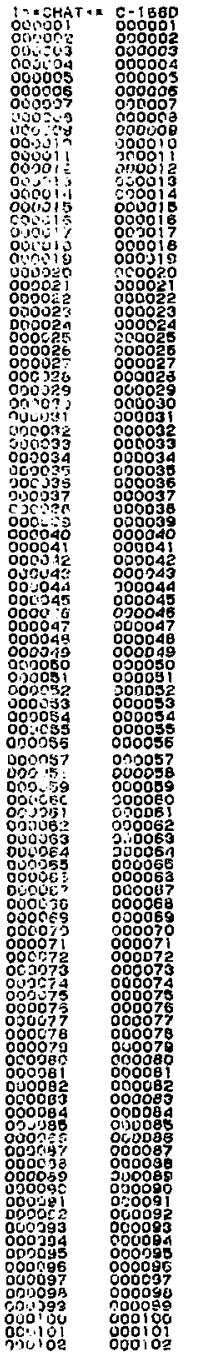

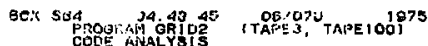

CODE ANALYSIS

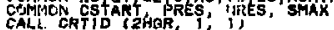

Con:

UNIT POLWT SOURCES PLOTTLD MORE THAR UNE if

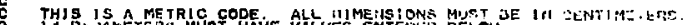

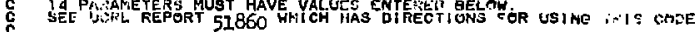

C PINHOLE RAOIUS

C PINHe

C PINHELE IENOTH

\& PINHOI.E BARR:ER THICISHESS

C MELY FTEE 'ATH OF RADIATIEN IN BAFR:ER MPTE!CiAL

AVFP = 3 , OT

C SOURCE PLANE UISTAMCE FREIA CIEMTER OF PIRHIJLE EARPIER

$20=102.8$

c IMACF. PI_LME DISTANCF FRON CENTER OF PINHOLE BARRIER

$25=197.5$

C IMAGE STNEEIV DEFINITION

E MAXIMUM aND MINIMUM " $X$ " VALUES ( $X$ EDoES) OF SCREEN XSMAX $=2,8$

¿ MAXIMUM AND MINIMUM "Y" VALLES IV EDOESI OF SCRËEIY YSTHAN $=2.6 .6$

$c$
$c$
$c$
$c$
$c$
$c$
$c$
$c$
$c$
$c$
$c$
$c$
$c$
$c$
$c$
$c$
$c$
$c$
$c$
$c$
$c$

UNIT POII.T SOUREE LOCATIONS ON " $X$ " AKIS OF SOURLE PLANE

SOUROES COMFINEE TO 10 LE $X$ LT RADIUS OF SOURCE PENUMBRA,

THE NUMBER OF UNIT POIRT SOURCES AND THE DISTANCE BE THEEN THEM ARE ENTERED BELOW.

"X" POSITION OF SUURCE NEAREST TO PINHOLE AXIS START $=$ O.

THE NUMUER OF INIT POIMT BOURCES TO BE ENTERED NUTBET $=3$

SEPARATION BEiWEeY POINT sQURCES GN " $K$ " AXIS OF SOURCE PLANE

c

C APDITIONAL TH!CKMESS AODED TO REAR OF PINHOLE GARFIER

PPNI SUNALUTHEE ONLY EXTRA $=40$.

č

If IA VALUES HPVE NOT GEEN ENTERED ABOVE, THIS CODE HILL NET RUN,

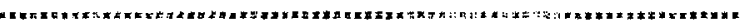

CSTART E START

MRES

CALL PINI

$T A A F !=2$. $* R / D$

$S R T=20^{2} \times$ TANF

EMdo $=(23+0) 2),(20-0 / 2$.

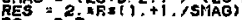

$R^{2}=R E$

FLR " T TAMFI/Z.

HFT" = T'?

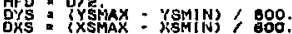

$\sin =0$.

LL 0

YMIN: YSMHN

CALL FRAME

CACL HAPO (KSMI H XSNIAX, YSMIN, YSHAX)

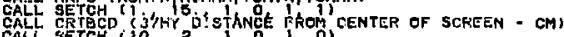

CALC SETCH i

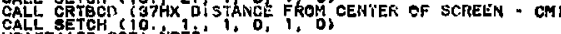

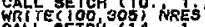

CALL SETCA '14:1 1

CM) 


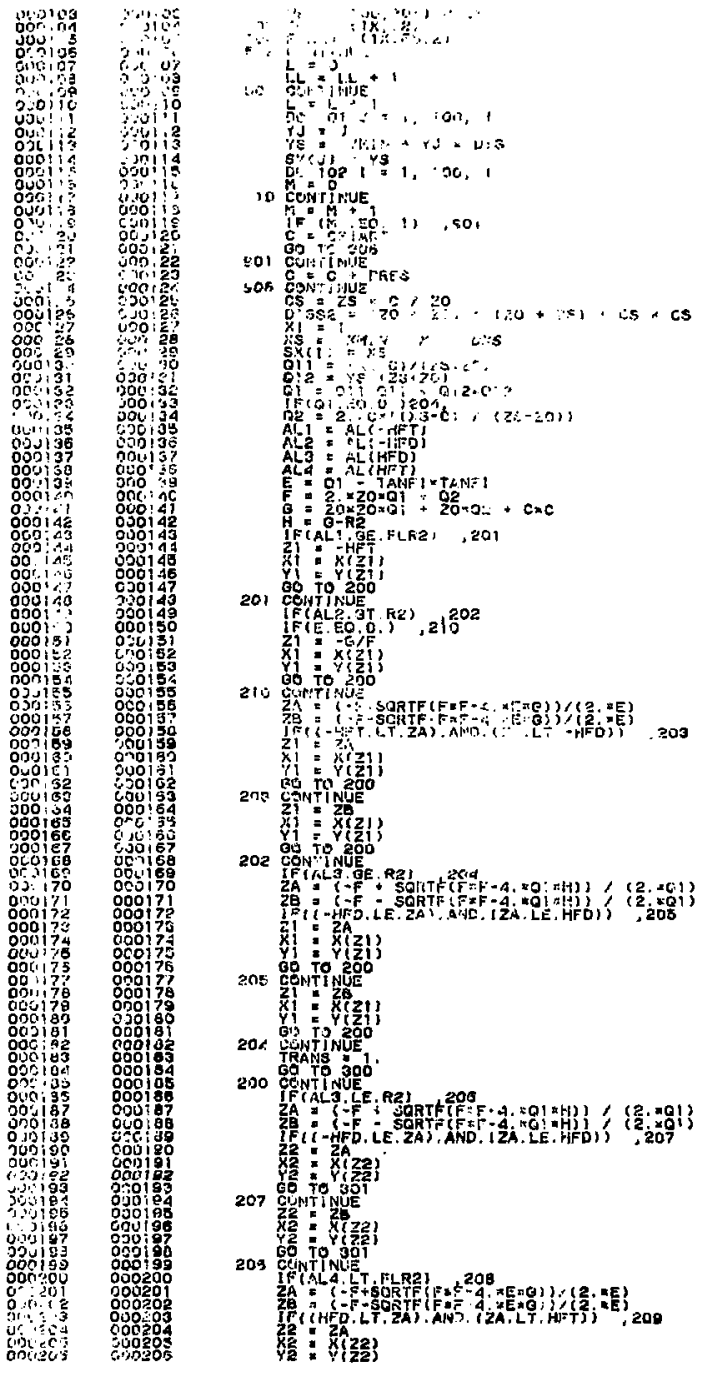




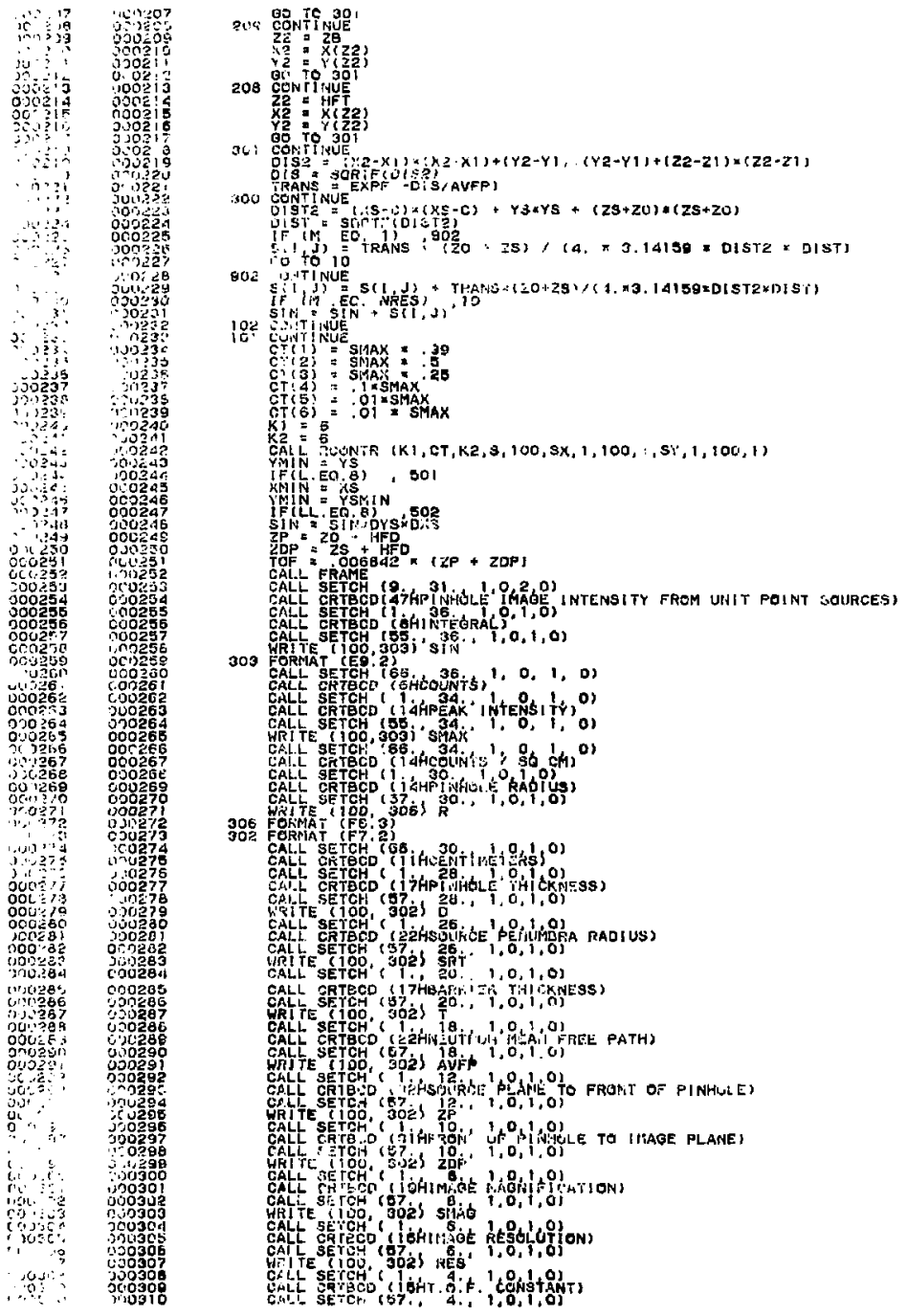




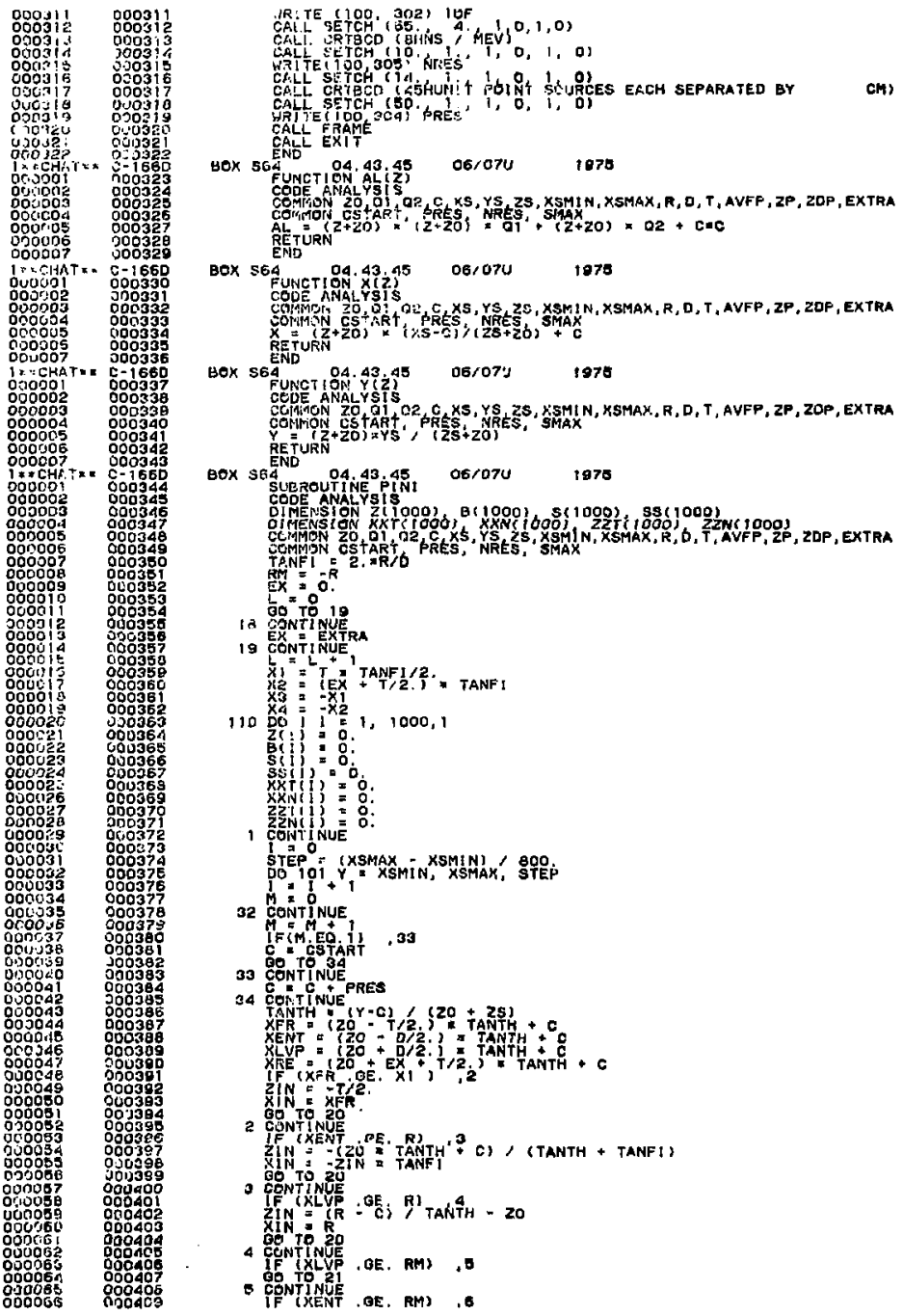




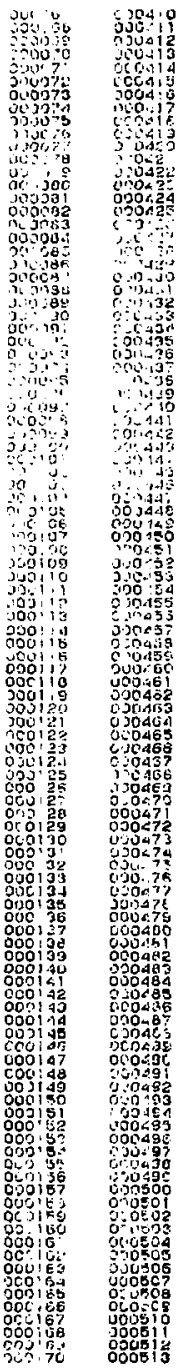

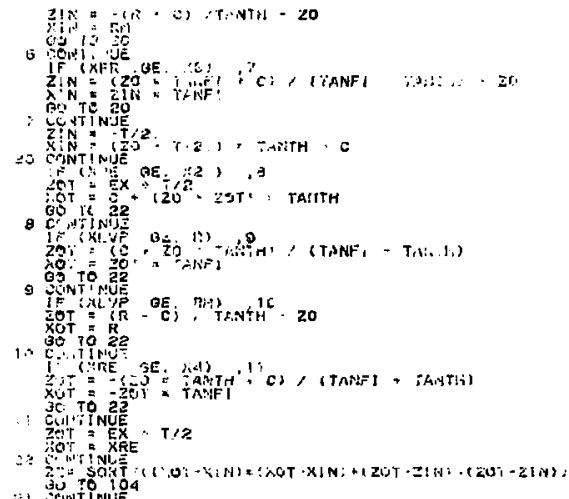

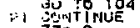

$z z_{0}=0$.

10. continus

Z!! $=Z \mathbf{Z}+(\geq 3+20)=$ TANTH

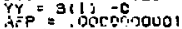

TRANS IEXPF (-ZI:), AVFP)

TRASS : EMPF (-211//AFP)

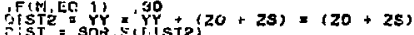

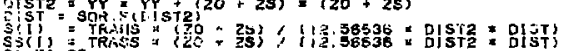

Qu fo jo

GSTZ $=Y Y=Y Y+(Z 0+78) \div 120+201$

DST= SOPTE(DIg)

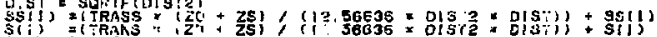

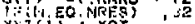

XXitis 3 xót

Xat? $=$ Kin

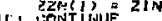

Constinue

YiglN: $\mathrm{XSHIN}$

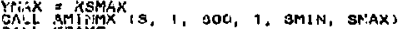

CALL TRAME

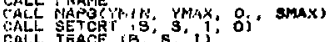

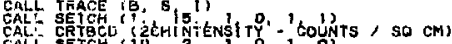

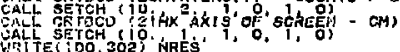

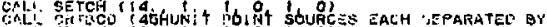

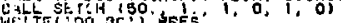

CH.

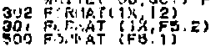

If i 20.1501

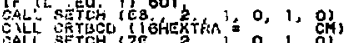

世ci

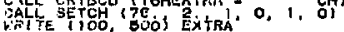

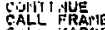

CrL, MAPKS!. CYMIN, YHAX, SMIN, SHAX)

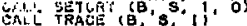

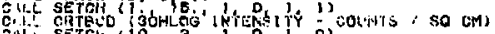

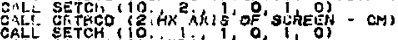

CALL EETCK (1O 'WAES'1, $0,1,0$

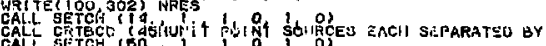

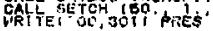




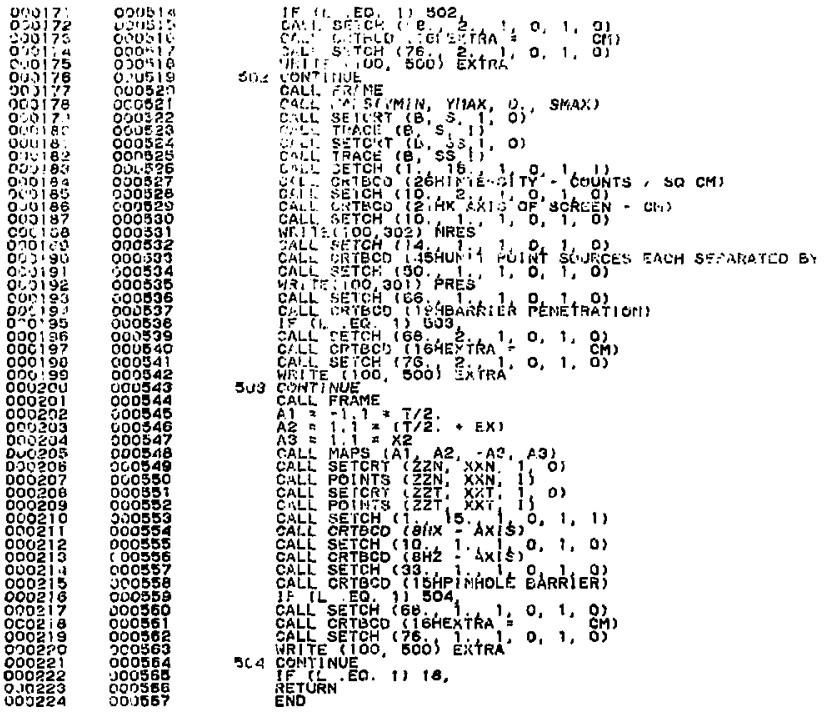

